Document downloaded from:

http://hdl.handle.net/10251/40611

This paper must be cited as:

Martí Albiñana, JV.; Gonzalez Vidosa, F.; Yepes Piqueras, V.; Alcalá González, J. (2013). Design of prestressed concrete precast road bridges with hybrid simulated annealing. Engineering Structures. 48:342-352. doi:10.1016/j.engstruct.2012.09.014.

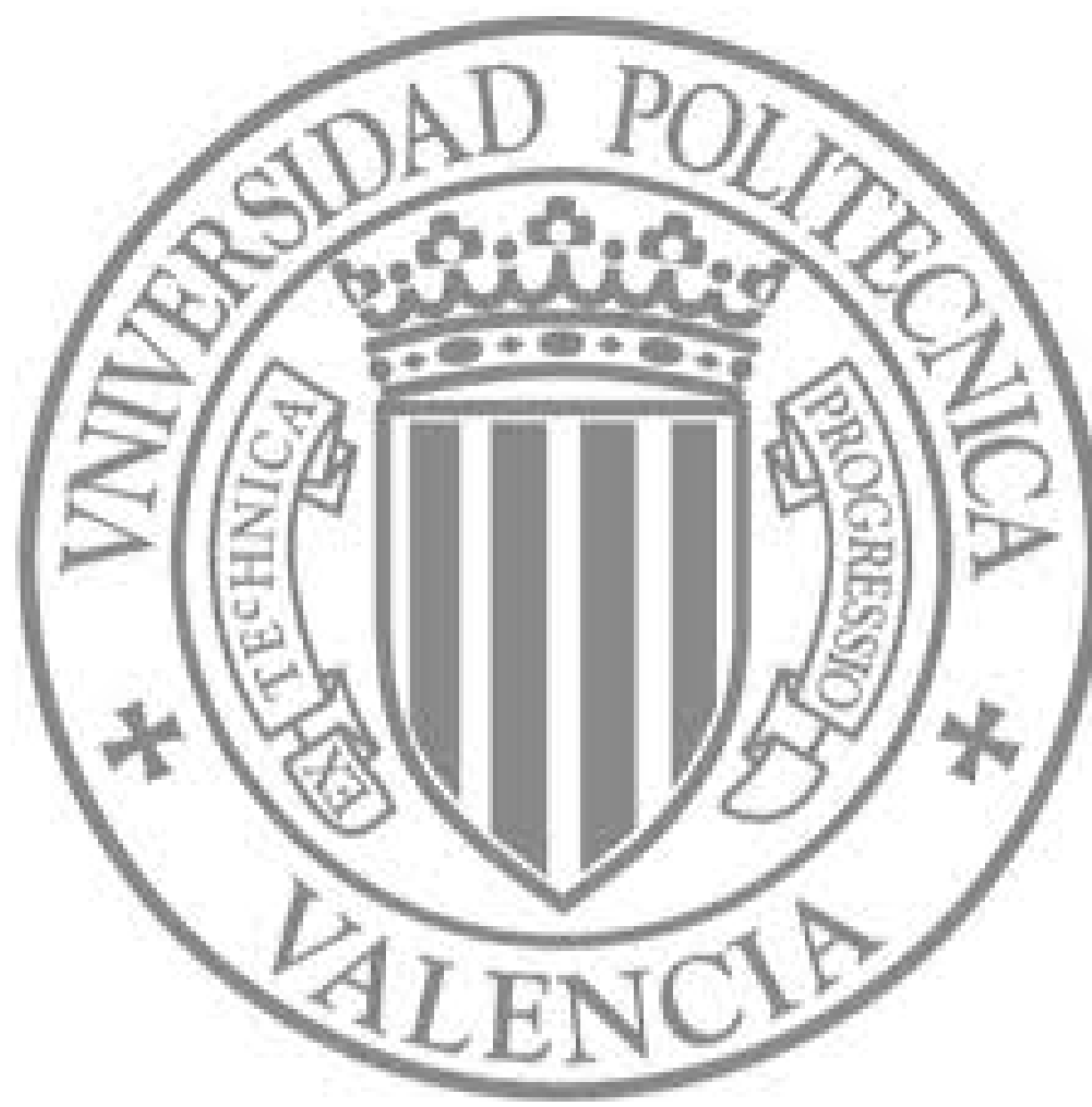

The final publication is available at

http://dx.doi.org/10.1016/j.engstruct.2012.09.014

Copyright Elsevier 


\section{Design of prestressed concrete precast road bridges with hybrid simulated}

\section{annealing}

José V. Martí ${ }^{1}$

Fernando Gonzalez-Vidosa ${ }^{2}$

Víctor Yepes ${ }^{3}$

Julián Alcalá $^{4}$

5160 WORDS + 32 REFERENCES, 18 FIGURES, 10 TABLES

\footnotetext{
${ }^{1}$ Associate Professor, ICITECH, Dept. of Construction Engineering, Universitat Politècnica de València, 46022 Valencia, Spain. E-mail: jvmartia@upv.es

${ }^{2}$ Professor, ICITECH, Dept. of Construction Engineering, Universitat Politècnica de València, 46022 Valencia, Spain. E-mail: fgonzale@upv.es

${ }^{3}$ Associate Professor, ICITECH, Dept. of Construction Engineering, Universitat Politècnica de València, 46022 Valencia, Spain. Corresponding author. Phone -34963879563; Fax: +34963877569; E-mail: vyepesp@upv.es

${ }^{4}$ Assistant Professor, ICITECH, Dept. of Construction Engineering, Universitat Politècnica de València, 46022 Valencia, Spain. E-mail: jualgon@upv.es
} 


\begin{abstract}
This paper describes one approach to the analysis and design of prestressed concrete precast road bridges, with double U-shaped cross-section and isostatic spans. The procedure used to solve the combinatorial problem is a variant of simulated annealing with a neighborhood move based on the mutation operator from the genetic algorithms (SAMO). This algorithm is applied to the economic cost of these structures at different stages of manufacturing, transportation and construction. The problem involved 59 discrete design variables for the geometry of the beam and the slab, materials in the two elements, as well as active and passive reinforcement. The parametric study showed a good correlation for the cost, geometric and reinforcement characteristics with the span length, which can be useful for the day-to-day design of PC precast bridges. A cost sensitivity analysis first indicates that a maximum $20 \%$ rise in steel costs leads to an $11.82 \%$ increase in the cost, while a $20 \%$ rise in concrete costs increases the cost up to $4.20 \%$, namely 2.8 times less. The analysis also indicated that the characteristics of the cost-optimized bridges are somewhat influenced by different economic scenarios for steel and concrete costs. Finally, there is a growth in the volume of concrete when the steel cost rises; surprisingly, the variation in the volume of concrete is almost insensitive to its rising price.
\end{abstract}

Keywords: Concrete structures, heuristic optimization, precast beams, prestressed concrete structures, simulated annealing, structural design. 


\section{Introduction}

Precast concrete construction technology presents economic opportunities when high production volumes are possible with a corresponding saving in costs. The basis of savings in materials and labor, a high quality product and workmanship as well as speed of construction are motives for using precast construction. However, today there are additional social and environmental benefits when using precast construction [1]. Bridge designers have taken advantage of this technology by specifying designs which utilize standard beams of comparatively short spans, typically ranging from 10 to over $40 \mathrm{~m}$ [2]. Reducing material weight is essential due to elevation and transportation costs. Another key aspect of precast structures is the use of prestressing, which significantly reduces the volume of concrete. In this context, structural optimization of this type of large and repetitive structures is an area of much research interest given the large amount of materials required in the manufacturing process.

Most traditional procedures for structural concrete design select initial solutions based on material grades, cross-section dimensions, and steel reinforcement based on sanctioned common practice. Once the structure is defined, it follows the analysis of the structure and checking the passive and active reinforcement. Should the dimensions, reinforcement or material grades be insufficient, the structure is redefined on a trial-and-error basis. This process is not automatic and leads to safe designs, but the cost of the concrete structures is, consequently, highly dependent upon the experience of the structural designer. Optimization methods are a clear alternative to experience-based methods. However, it is worth mentioning that experience is crucial for the development of computer design models since design involves more than a mere application of codes of practice. This means that experience will move beyond preliminary design decisions to the judgment required to develop computer design models.

Applying optimization techniques to the concrete structures design is deemed both convenient and feasible since the structural design is made more efficient. In general terms, structural optimization can be addressed using either exact or heuristic methods. These methods are efficient when using only a few design variables, but computing time becomes prohibitive when large numbers of variables are required. A review of non-heuristic structural concrete optimization studies can be found in Sarma and Adeli [3], but now it is possible to use heuristic search methods to provide good solutions at a reasonable computational cost at the risk of sub-optimality. Much research has been conducted with regard to heuristic methods, such as genetic algorithms (GAs), simulated annealing (SA), threshold accepting (TA), ant colony optimization (ACO), and particle swarm optimization (PSO), among others [4-8]. Heuristic optimization has been used with success in different areas of structural engineering [9]. A thorough review of structural optimization methods was conducted by Cohn and Dinovitzer 
[10], who emphasized the gap between theoretical studies and the practical applications, confirming that most research focused on steel structures, whereas only few dealt with concrete structures. The earliest studies into the structural concrete optimization for beams date back to the late 1990s [11,12]. Many later studies have been undertaken to implement evolutionary programming, in particular GAs, to solve structural concrete optimization problems. Kicinger et al. [13] provided a review of evolutionary programming and structural design, while the present authors' research group recently reported on non-evolutionary techniques to optimize retaining walls, frame bridges, building frames, bridge piers, prestressed concrete (PC) precast pedestrian bridges, and road vaults [14-20].

Following this line of work, this paper focuses on the economic optimization of PC precast road bridges like those common in road construction. These bridges are typically formed by two isostatic beams, with a double U-shaped cross-section which integrates an upper reinforced concrete slab for road traffic (Fig. 1). Typical span lengths range from 20 to $40 \mathrm{~m}$. This is a typically composite design where the slab acts as the compression member while the beams largely serve to take tension. The methodology consisted in developing a computer evaluation module in which cross-section dimensions, materials and steel reinforcement were taken as discrete variables. This module computed the cost of a solution and checked all the relevant limit states. A hybrid SA algorithm with mutation operator (abbreviated herein as SAMO) was then used to search the solution space to identify a set of solutions with optimized values for the designer. The rest of this paper is organized as follows. In Section 2, we define the optimization problem while in Section 3, we explain the heuristic method developed. In Section 4, we describe the resulting computational experience with SAMO algorithm and a parametric study, and in Section 5, we relate a study of cost sensitivity. Finally, conclusions and suggestions for further research are made in Section 6.

\section{Problem definition}

\subsection{Optimization problem definition}

In this study, the structural design problem is the cost minimization of a PC precast road bridge, represented by the objective function $f$ in Eq. (2.1) while satisfying the constraints in Eq. (2.2).

$$
\begin{aligned}
& C=f\left(x_{1}, x_{2}, \ldots, x_{n}\right) \\
& g_{j}\left(x_{1}, x_{2}, \ldots . x_{n}\right) \leq 0
\end{aligned}
$$




$$
x_{i} \in\left(d_{i 1}, d_{i 2}, \ldots, d_{i q_{i}}\right)
$$

Note that $x_{1}, x_{2}, \ldots, x_{\mathrm{n}}$ are the design variables whose combination is to be optimized (Section 2.2). Each variable can take on the discrete values listed in Eq. (2.3). The remaining data necessary to calculate the structure are the parameters of the problem (Section 2.3). The objective function $f$ in Eq. (2.1) expresses the cost of building the structure as the sum of unit prices multiplied by the measurements of construction units (Section 2.4). The constraints $g_{j}$ in Eq. (2.2) are all the serviceability limit states (SLSs) and ultimate limit states (ULSs) that must be met by the structure, as well as the geometric and constructability constraints of the problem (Section 2.5).

\subsection{Design variables}

The design variables are the magnitudes subject to optimization. The analysis includes 59 design variables (see Fig. 2). Variables include seven geometric values: the depth of the beam $\left(h_{1}\right)$, the width of the soffit of the beam $\left(b_{1}\right)$ and the thickness of the bottom flange $\left(e_{1}\right)$, the width and thickness of the top flanges of the beam $\left(b_{3}\right.$ and $\left.e_{3}\right)$, the thickness of the webs $\left(e_{2}\right)$ and the thickness of the slab $\left(e_{4}\right)$. Regarding material strength, two variables define the concrete type of the slab and the beam. Prestressing is defined by four variables: the number of strands in the top flanges and the number of strands in the first, second and third layers of the bottom flange. Finally, 46 variables define the bar diameters, the spacing and the bar lengths of the reinforcement following a standard set-up for the beam and the top slab (Fig. 2). All variables are discrete since the final solution has to be constructable.

The solution space is defined by the set of combinations of values for the 59 variables. Such space is, in practice, unlimited due to what is known as combinatorial explosion; the number of combinations in this case is on the order of $10^{65}$. Each vector of 59 variables determines a solution whose economic cost is given by Eq. (2.1). Solutions that satisfy the constraints of the limit states in Eq. (2.2) are called feasible solutions, and those that do not are deemed unfeasible solutions.

\subsection{Design parameters with fixed values}

The parameters of the analysis are all fixed quantities and therefore they are not subject to optimization. They relate to the actions considered, geometric values, partial safety coefficients and durability data. The total number of parameters is 23 , the most important of which are the free span, the spacing between beams, the width of the top slab, the inclination of the webs, the dead loads acting on the bridge, the type of active and passive reinforcing steel, the ambient conditions and the partial coefficients of safety. Fig. 3 shows the main beam-slab parameters and Table 1 provides details of those parameters for the PC precast bridge analyzed. The slenderness of the beam is limited to a minimum of $\mathrm{L} / 18$ due to aesthetic ground and specific road transportation considerations, where $L$ is the span length. Otherwise, the optimization algorithm tends to increase continuously the depth of the beam. 


\subsection{Cost function}

The objective function considered is the cost function defined in Eq. (2.4), where $p_{i}$ are the unit prices; $m_{i}$ are the measurements of the units in which the construction of the PC precast bridge is split, and $r$ is the total number of construction units.

$$
C=\sum_{i=1, r} p_{i} \times m_{i}
$$

The cost function includes the value of materials (concrete, active prestressing steel, passive reinforcement steel) and all the entries required to evaluate the entire cost of the bridge construction process. The basic prices considered were obtained from a 2008 survey of national contractors and subcontractors of precast structures and are given in Tables 2, 3, 4 and 5. Note that Table 3 includes a correction in the price for passive reinforcement whose diameter is different from the standard price for $12 \mathrm{~mm}$ diameter $(25 \mathrm{~mm}$ and $32 \mathrm{~mm}$ reinforcement diameters are not used in beams). Table 4 includes the costs of beam transport depending on its maximum weight, supposing a distance up to $20 \mathrm{~km}$, one way. Table 5 summarizes the placing beam cost depending on the maximum beam length for standard difficulty conditions. It is worth noting that other studies transform constrained into unconstrained problems by means of penalty functions. This study, however, is restricted to feasible solutions only, and therefore penalty functions are not applied.

\subsection{Structural evaluation module}

Considering all the data necessary to define a given structure, the structural evaluation module calculates the stress envelopes and checks all the limit states and the geometric constraints represented by Eq. (2.2). This evaluation module requires the structure to be defined in terms of design variables and the coding of all the structural constraints to be satisfied. The main advantage of this approach is that it leads to optimal design and automation, i.e., the design variables are determined by the optimization process and not by the engineer.

Structural constraints considered followed standard provisions for the Spanish design of this type of structure [21,22], and included checks of the serviceability and ULSs of flexure and shear for the stress envelopes due to the loads. According to the Spanish Concrete Code [21] the limit state of failure due to shear will be reached when either the compressive strength of the web or its tensile strength is exhausted; as a result, it was verified that both conditions were simultaneously satisfied. The variable traffic load considered is a uniformly distributed load of 4.0 $\mathrm{kN} / \mathrm{m}^{2}$ and a point load of $600 \mathrm{kN}$. The dead load considered is a wearing surface of $0.09 \mathrm{~m}$ as well as a uniformly distributed load of $2 \times 0.5 \mathrm{kN} / \mathrm{m}^{2}$ for concrete bridge barrier rails installed along the edge of the deck. A precast reinforced concrete slabs of $0.06 \mathrm{~m}$ width as formwork of the top concrete slab has been taken into account. The 
behavior of this type of bridges is a complex process due to the phased construction and the interaction between the precast beam and the cast-in-place along the time [23]. For this reason, the construction sequences have been considered in order to design the elements and analyse the structural response of the bridge in each phase. In addition, slab shrinkage, limited by the precast beam to which it is connected, may give rise to delayed cracking in the slab if the tension generated exceeds its tensile strength; however, a typically difference in age of one month has been considered between slab and beam concrete in order to consider this effect. The slap can be poured transversally in several phases in order to save prestressing steel [23]; however, the top cast-in-place slab in this kind of structure is usually poured in a single step for practical reasons. Firstly, a 20-bar structural model was used for a linear elastic analysis of the beam before being connected to the slab; in this phase, the elastic shortening of concrete has been taken into account when calculating the short-term prestress loss. Then, stress resultants and reactions were calculated taking into account long-term prestress loss due to creep and shrinkage of concrete and prestressing steel relaxation by a stiffness matrix program using a 2-D mesh with 20 bars and 21 sections for each U-shaped beam, which are connected with three bars for each of the 21 sections. Fig. 4 shows a detail of the entire bar model with 103 bars and 84 nodes, for which a linear elastic analysis including gross section properties was used.

When the deflections and the envelopes of stress resultants are known, all the ULSs and SLSs are checked in accordance with the Spanish Concrete Code [21]. In this sense, it is worthy to note that the model evaluates the relevant limit states following standard design office procedures. Note that once the variables defining a frame solution are chosen, then geometry, materials, active and passive reinforcement are fully defined. It is important to note that no attempt is made to calculate the reinforcement according to the usual design rules. Such common design procedures follow a conventional order to obtain reinforcement bars from flexural-shear ULSs and then checking SLSs and redefining if necessary. This order is effective, yet it ignores other possibilities that heuristic search algorithms do not overlook. In this sense, for example, it is possible to suppress shear reinforcement by increasing flexural reinforcement, which may result in a more economical design.

The calculation of the ULS of flexure in beams checks whether the acting bending resultant, $M_{d}$, is within the ultimate iteration diagram $N_{u}-M_{u}$. Moreover, the ULS for shear verifies that the two ultimate values are greater than the factored acting shear. Both flexural and shear minimum amounts of reinforcement, as well as the geometric minimum, are also examined. The SLS for cracking includes compliance with the crack width limitation for existing durability conditions. Deflections were limited to $1 / 1000$ of the free span length for the quasi-permanent combination. Fatigue of concrete and steel was not considered since this ULS is rarely checked in 
this type of bridges. Reinforcement setup to resist local stresses and avoid cracking in D-regions can be designed independently so it was not considered in the optimization process. The same can be said about the beams end diaphragms reinforcement design. However, the beams end diaphragms have been taken into account for each beam in the modeling of the structure. The durability limit state is checked specifically according to the design value of the service working life. The design is checked at each iteration.

\section{Hybrid simulated annealing algorithm with mutation operator}

The method used in the present work is a hybrid SA algorithm with a mutation operator (SAMO). SA was developed by Kirkpatrick et al. [5] to find the best solution of a combinatorial optimization problem. The practical application of the algorithm is thoroughly described by Dreo et al. [24]. Annealing is a physical process often performed in order to relax the system to a state with minimum free energy. Based on the annealing process in statistical mechanics, SA is inspired by simulation of crystal formation from masses melted at high temperatures and cooled slowly. At high temperatures, configurations of energy greater than previous ones may randomly form; nevertheless, as the mass cools, the probability of higher energy configurations forming decreases. The criterion to accept new solutions for the algorithm is governed by the expression $\exp (-\Delta E / T)$, where $\Delta E$ is the increment in the objective function value of the new configuration being optimized, and $T$ is a positive control parameter named temperature. The algorithm starts with a feasible random solution and a high initial temperature. Then, SA attempts to move from the initial working solution to one of the neighborhood solutions. The new current solution is evaluated in terms of cost. Greater cost solutions are accepted when a uniform random number from $(0,1)$ is smaller than $\exp (-\Delta E / T)$. The current solution is then checked against structural constraints and if it is feasible, it is adopted as the new working solution. The parameter $T$ is decreased geometrically $(T=k T)$ by means of a coefficient of cooling $k$. A number of iterations called a Markov chain is allowed at each step of temperature. The algorithm stops when the temperature is a small percentage of the initial temperature or when there are no improvements in a number of Markov chains. SA is capable of surpassing local optima at high-medium temperatures and gradually converges as the temperature falls to zero. Asymptotically SA algorithm finds an optimal solution with probability one [25]; fortunately, a finite-time implementation of the algorithm returns near-optimal solutions for most problem instances [26]. The SA method requires calibrating the initial temperature, the length of the Markov chains and the cooling coefficient. Adopted values of this work will be given below. The initial temperature was adjusted following the method proposed by Medina [27], which consists in choosing an initial value and checking whether the percentage of acceptances of higher energy solutions is between $20-40$ percent. If the percentage is 
greater than $40 \%$, the initial temperature is halved; and if it is smaller than $20 \%$, the initial temperature is doubled.

On the other hand, GAs are population-search procedures that mimic the process of natural evolution [4]. GAs explore the solution space using a population of solutions and operators such as selection, crossover and mutation. Generally speaking, GA produces diversified solutions but presents poor convergence properties in contrast to SA, which may not be able to explore the whole solution space without an appropriate neighborhood structure. Some researchers [28,29] have implemented a hybrid strategy which combines the synergy effect between the GA and SA and have obtained encouraging results. The idea is to employ SA with a neighborhood move based on the mutation operator from the GA [30]; thus, the current solution is changed by a small random change in the values of the variables. Fig. 5 shows a flowchart of the simulated process.

\section{Results from numerical experiments and parametrical study}

In this Section, we examine the results from computational experiments involving SAMO optimization applied to a PC precast road bridge with a $35 \mathrm{~m}$ span (center-to-center distance between bearings) and a $12.00 \mathrm{~m}$ width, considering the parameters defined in Table 1. The algorithm was coded in Fortran 95 with a Compaq Visual Fortran Professional 6.6.0 compiler. A personal computer with an INTEL Core TM2 Quad CPU Q6600 processor with $2.40 \mathrm{GHz}$ needed about 300 minutes to run the proposed SAMO algorithm. The application of the SAMO algorithm requires the definition of the cooling coefficient value $(r)$ as well as the length of the Markov chain $\left(L_{M}\right)$. After several experiments, the first initial temperature trial was adjusted to $0.5 \%$ of the cost of the initial solution; the most efficient mutation found consisted in a random variation of nine variables of the problem, and the stop criterion was $2 \%$ of the initial temperature or two chains without improvement. Fig. 6 shows a typical evolution of the cost with the computing time for the SAMO algorithm. Mutation was based on a small random perturbation to the values of some of the variables that define the current solution. These small random variations were selected to avoid a totally random search in the solution space, and they are justified for practical and constructive processes. Note that the final result of the heuristic procedure are dependent on the control parameters of the algorithm and that those adopted herein were the result of a study of alternatives in the study by Martí [31]. Thus, in order to obtain the calibration or the SAMO parameters, the algorithm was run 144 times (computer runs were performed nine times for each combination of 16 parameters). Table 6 shows the results of a 16 case-study series as well as the minimum, mean and deviation of the mean with respect to the minimum for the costs. S3 is the heuristic that provides a lower average cost $(110,477 €)$ and a very small deviation with respect to the minimum cost $(1.35 \%)$ with an average computational cost of 18,322 seconds. Therefore, the calibration of the SAMO parameters 
recommended Markov chains of $L_{M}=2500$ iterations as well as a cooling coefficient of $r=0.95$.

A parametric study for varying span lengths with the SAMO optimization model is presented. Five span lengths of 20,25, 30, 35 and $40 \mathrm{~m}$ were considered. The primary economic, geometric and reinforcement characteristics are examined. Features of the optimized solutions are compiled in Tables 7-9: Table 7 gives the main geometry of the solutions, together with the concrete grade and amount of prestressing steel; Table 8 gives the basic measurements of concrete and reinforcing steel, and Table 9 lists the reinforcing details of the cross-section at the supports. The results of the parametric study lead to practical rules for the preliminary design of cost-optimized PC precast road bridges, with a double U-shaped cross-section and isostatic spans. The results are discussed together with those of a regression analysis. The corresponding functions are valid approximations within the range of the studied parameters and therefore careful consideration is required when extrapolation is carried out.

Fig. 7 shows the average results related to the total cost of the PC precast road bridges for distinct span lengths. The total cost evolution as a function of the horizontal span leads to a very good linear correlation. (The average bridge cost adjusts to $C=3368.4 L-7222.8$ with a regression coefficient of $R^{2}=0.996$.) The cost increments of the bridges are due to higher material costs, necessary to resist increased slab forces and to satisfy deflection requirements. The total costs increase on average by a factor of 2.07 when the span increases from $20 \mathrm{~m}$ to $40 \mathrm{~m}$. Note that the $R^{2}$ regression coefficient in Fig. 7 is almost 1, which indicates a nearly functional relation. The SAMO variations of the mean and minimum cost for different span lengths are lower than $2.2 \%$. It is worth noting that other models developed by the authors exhibit more scatter. For example, the precast pedestrian bridge SA-model developed by Martí and González-Vidosa [18] showed a 5.8\% deviation and, hence, the present PC precast road bridge model is regarded by the authors as robust and quite accurate.

Fig. 8 shows the mean depth of the beam $\left(h_{1}\right)$ for different span lengths. The depth of the beam has a good linear variation in terms of the span length of the bridge. (The average depth of the beam adjusts to $h_{1}=0.0548 L+$ 0.0052 with $R^{2}=0.9997$.) Again, the high correlation factor of nearly one indicates an almost functional relation. The reason for this can be explained by the fact that the ratio $\mathrm{L} / h_{1}$ has been always lower than 18 (see Table 1 ).

As shown in Fig. 9, a linear correlation is found for the thickness of the slab $\left(e_{4}\right)$ with varying span lengths. Values of $e_{4}$ decrease with the span length, which means that the SOMA algorithm tries to find a lighter weight solution, but increases the concrete characteristic resistance. (The average thickness of the slab adjusts to $e_{4}=$ $-0.0029 L+0.3098$ with $R^{2}=0.8482$.) Regarding the average of strands in relation to the span, Fig. 10 illustrates its variation with the span length of the bridge. (The average number of strands adjusts to \#strands $=1.453 L+5.588$ 
with $R^{2}=0.9976$.)

The mean characteristic compressive strength of concrete in the beam $\left(f_{c, \text { beam }}\right)$ is high, ranging linearly from $50 \mathrm{MPa}$ to $45 \mathrm{MPa}$ when the span length increases from $20 \mathrm{~m}$ to $40 \mathrm{~m}$ (Fig. 11). Note that the highest concrete grade that was considered in the optimization problem is $50 \mathrm{MPa}$. (The mean characteristic compressive strength of concrete in the beam adjusts to $f_{c, \text { beam }}=-0.2224 L+53.849$ with $R^{2}=0.751$.) In regard to the slab (Fig. 11), a very good adjustment is achieved using a quadratic function. (The mean characteristic compressive strength of concrete in the slab adjusts to $f_{c, s l a b}=0.019 L^{2}-0.8973 L+45.398$ with $R^{2}=0.9981$.) The mean $f_{c, s l a b}$ increases from $35 \mathrm{MPa}$ to $45 \mathrm{MPa}$, particularly with a span length of $30 \mathrm{~m}$.

Fig. 12 illustrates the variation of the width of the soffit of the beam $\left(b_{1}\right)$ with the span length. This width has a slight tendency to decrease when the span increases in length. (The mean width of the soffit of the beam adjusts to $b_{1}=-0.0051 L+2.1034$ with $R^{2}=0.7234$.) Although Fig. 13 does not show a clear correlation between the thickness of the bottom flange $\left(e_{1}\right)$ and the span length, there is a growing trend for $e_{1}$ when the span length is longer than $25 \mathrm{~m}$. (The mean thickness of the bottom flange adjusts to $e_{1}=0.0002 L^{2}-0.0098 L+0.2924$ with $R^{2}=$ 0.7996.)

Regarding ratio of the volume of concrete $\left(v_{c}\right)$ and the surface of the slab $\left(s_{s}\right)$, Fig. 14 illustrates a very slight tendency to reduce the amount of concrete with the span length. This is surprising since an increase in the span length implies an increase in the depth of the beam; however, both the width of the soffit of the beam as well as the thickness of the bottom flange decrease with the depth of the beam (see Fig. 12 and 13). The average amount of concrete required is $0.344 \mathrm{~m}^{3} / \mathrm{m}^{2}$, ranging from $0.33-0.37 \mathrm{~m}^{3} / \mathrm{m}^{2}$. (The mean ratio of the volume of concrete in relation to the surface of the slab adjusts to $v_{c} / s_{s}=-0.0006 L+0.3636$ with $R^{2}=0.1397$.)

Another ratio of interest is the passive reinforcement $\left(p_{r}\right)$ of the bridge in relation to the surface of the slab $\left(s_{s}\right)$. Fig. 15 shows its variation with the span length. Values vary from $55.73 \mathrm{~kg} / \mathrm{m}^{2}$ for a span length of $20 \mathrm{~m}$ to $61.23 \mathrm{~kg} / \mathrm{m}^{2}$ for a span length of $40 \mathrm{~m}$. (The mean ratio of the passive reinforcement of the bridge in relation to the surface of the slab $p_{r} / s_{s}=0.2496 \mathrm{~L}+51.06$ with $R^{2}=0.8728$.)

The thickness of the webs $\left(e_{2}\right)$ was $0.10 \mathrm{~m}$ in all cases. The average width of the top flanges of the beam $\left(b_{3}\right)$ is $0.27 \mathrm{~m}$, ranging from $0.25 \mathrm{~m}$ to $0.28 \mathrm{~m}$. There is no clear tendency for this width with the span length of the beam. The same is true for the thickness of the top flanges of the beam $\left(e_{3}\right)$, whose average value is $0.20 \mathrm{~m}$, varying from $0.18 \mathrm{~m}$ to $0.21 \mathrm{~m}$.

\section{Cost sensitivity analysis}


In this section, the sensitivity of the unit costs is analyzed. The goal is to evaluate the new solutions when the steel cost or the concrete cost rises. One expects that a change in the unit prices would result in a modification of the optimum structure. To this end, four steel price increases of 5\%,10\%,15\% and $20 \%$ were considered, keeping the concrete cost. Conversely, concrete cost was increased by $5 \%$ to $20 \%$, in steps of $5 \%$ keeping both active and passive reinforcement steel cost. According to Section 4, the SAMO algorithm was applied to a PC precast road bridge with a $35 \mathrm{~m}$ span. Fig. 16 indicates that the cost impact is greater when the unit price increase occurs in the steel. Thus, a maximum $20 \%$ rise in the steel unit price leads to $11.82 \%$ increase in the cost, while $20 \%$ rise in the concrete unit price increases the cost up to $4.20 \%$, namely 2.8 times less.

Table 10 summarizes mean solutions for different economic scenarios for steel and concrete costs. The depth of the beam $\left(h_{1}\right)$ is practically constant, so that the solutions maintain the ratio $\mathrm{L} / h_{1}$ always lower than 18 . There is no clear relationship between the remaining variables in Table 10 and the change in unit prices. This determination in the geometry would be constrained by the difficulty in finding a suitable cross-section compatible with the prestressing actions. These results are consistent with the findings of Perea et al. [32] for road box frames, where the characteristics of the cost-optimized structures are somewhat influenced by the steel or concrete prices.

Fig. 17 illustrates the variation of the active and passive reinforcement quantity required in accordance with change in costs in relation to the surface of the slab. Looking at the trend lines, we find a decrease in the steel quantity in accordance with a higher steel cost. Conversely, there is a logical increase in the steel quantity when the concrete is more expensive. However, the steel quantity is more sensitive to changes in steel cost than the concrete costs. Likewise, Fig. 18 shows the rise in the volume of concrete when the steel cost rises and the steel quantity is smaller as its price increases. As before, this effect is more pronounced with the variation in steel costs. Surprisingly, in this case the variation in the volume of concrete is almost insensitive to its rising cost.

\section{Concluding remarks}

In this paper we describe an algorithm which is useful for the automatic design as well as cost minimization of PC precast road bridges, typically formed by two isostatic beams, with a double U-shaped cross-section, based on a hybrid SA strategy with mutation operators named SAMO. From the research conducted, the following conclusions may be drawn:

- The results show the potential applicability of heuristic algorithms for the advanced automatic design of real PC precast road bridges. It is essential to note that the present model eliminates the need for experience-based rules of design. 
- The proposed SAMO algorithm combines the synergy effect between the GA and SA employing a neighborhood move based on a mutation operator. The calibrated algorithm involves a mutation operator of nine variables, the initial temperature by Medina's method, Markov chains of 2500 iterations, a cooling coefficient of 0.95 and a stop criterion of $2 \%$ of the initial temperature or two chains without improvement.

- The parametric study shows a good correlation for the cost, geometric and reinforcement characteristics with the beam span length, which can be useful for the day-to-day design of PC precast bridges. However, there is no clear tendency in the thickness of the web nor in the width of the top flanges of the beam with the span of the beam.

- A cost sensitivity analysis applied to a PC precast bridge with a $35 \mathrm{~m}$ span indicates that the cost impact is greater when the unit price increase affects steel. Thus, a maximum $20 \%$ rise in the steel unit price leads to an $11.82 \%$ increase in the cost, while $20 \%$ rise in the concrete unit price increases the cost up to $4.20 \%$, namely 2.8 times less.

- The characteristics of the cost-optimized structures are somewhat influenced by different economic scenarios for steel and concrete prices. However, an increase in the steel cost reduces the steel quantity whereas an increase in the concrete cost results in a slight increase in the steel quantity. In addition, there is a rise in the volume of concrete when the steel price rises; surprisingly, the variation in the volume of concrete is almost insensitive to its rising price.

\section{Acknowledgements}

This work was supported by the Universitat Politècnica de València (Research Project PAID-06-09), the Spanish Ministry of Science and Innovation (Research Project BIA2011-23602) and the European Community with the FEDER funds. The authors are grateful to the anonymous reviewers for their constructive comments and useful suggestions. The authors are also grateful to Dr. Debra Westall for her thorough revision of the manuscript.

\section{References}

[1] Yee, AA. Social and environmental benefits of precast concrete technology. PCI J 2001;46(3):14-20.

[2] Harris, F. Modern construction and ground engineering equipment and methods. Essex: Prentice Hall; 1994.

[3] Sarma KC, Adeli H. Cost optimization of concrete structures. ASCE J Struct Eng 1998;124(5):570-8.

[4] Holland JH. Adaptation in natural and artificial systems. Ann Arbor: University of Michigan Press; 1975.

[5] Kirkpatrick S, Gelatt CD, Vecchi MP. Optimization by simulated annealing. Science 1983;220(4598):671-80. 
[6] Dueck G, Scheuer T. Threshold accepting: a general purpose optimization algorithm superior to simulated annealing. J Comput Phys 1990;90(1):161-75.

[7] Dorigo M, Maniezzo V, Colorni A. The ant system: optimization by a colony of cooperating agents. IEEE Trans Syst Man Cybern Part B 1996;26(1):29-41.

[8] Kennedy J, Eberhart R. Particle swarm optimization. In: IEEE international conference on neural networks, vol. IV. Piscataway: NJ; 1995. p. 1942-8.

[9] Yepes V, Medina JR. Economic heuristic optimization for the heterogeneous fleet VRPHESTW. ASCE J Transp Eng 2006;132(4):303-11.

[10] Cohn MZ, Dinovitzer AS. Application of structural optimization. ASCE J Struct Eng 1994;120(2):617-49.

[11] Balling RJ, Yao X. Optimization of reinforced concrete frames. ASCE J Struct Eng 1997;123(2):193-202.

[12] Coello CA, Christiansen AD, Santos F. A simple genetic algorithm for the design of reinforced concrete beams. Eng Comput 1997;13:185-96.

[13] Kicinger R, Arciszewski T, de Jong K. Evolutionary computation and structural design: A survey of the state-of-the-art. Comput Struct 2005;83:1943-78.

[14] Yepes V, Alcala J, Perea C, Gonzalez-Vidosa, F. A parametric study of optimum earth retaining walls by simulated annealing. Eng Struct 2008;30(3):821-30.

[15] Perea C, Alcala J, Yepes V, Gonzalez-Vidosa F, Hospitaler A. Design of reinforced concrete bridge frames by heuristic optimization. Adv Eng Softw 2008;39(8):676-88.

[16] Paya-Zaforteza I, Yepes V, Hospitaler A, Gonzalez-Vidosa F. $\mathrm{CO}_{2}$-efficient design of reinforced concrete building frames. Eng Struct 2009;31(7):1501-8.

[17] Martinez FJ, Gonzalez-Vidosa F, Hospitaler A, Yepes V. Heuristic optimization of RC bridge piers with rectangular hollow sections. Comput Struct 2010;88(5-6):375-86.

[18] Marti JV, Gonzalez-Vidosa F. Design of prestressed concrete precast pedestrian bridges by heuristic optimization. Adv Eng Softw 2010;41(7-8):916-22.

[19] Martinez FJ, Gonzalez-Vidosa F, Hospitaler A, Alcala J. Design of tall bridge piers by ant colony optimization. Eng Struct 2011;33(8):2320-9.

[20] Carbonell A, Gonzalez-Vidosa F, Yepes V. Design of reinforced concrete road vaults by heuristic optimization. Adv Eng Softw 2011;42(4):151-9.

[21] Fomento M. EHE: Code of structural concrete. Madrid: Fomento; 2008 [in Spanish].

[22] Fomento M. IAP-98: Code on the actions for the design of road bridges. Madrid: Fomento; 1998 [in Spanish]. 
[23] Marí AR, Montaler J. Continuous precast concrete girder and slab bridge decks. Proc ICE-Struct Build 2000;140(3):195-206.

[24] Dreo J, Petrowsky A, Siarry P, Taillard E. Metaheuristics for hard optimization. Methods and case studies. Berlin Heidelberg: Springer; 2006.

[25] Lundy M, Mees A. Convergence of an Annealing Algorithm. Math Prog 1986, 34:111-24.

[26] Aarts E, Korst J. Simulated annealing and Bolzmann machines: a stochastic approach to combinatorial optimization and neural computing. John Wiley \& Sons, Inc., Chinchester, UK, 1989.

[27] Medina JR. Estimation of incident and reflected waves using simulated annealing. ASCE J Waterway Port Coast Ocean Eng 2001;127(4):213-21.

[28] Wong SYW. Hybrid simulated annealing/genetic algorithm approach to short-term hydro-thermal scheduling with multiple thermal plants. Int J Electr Power Energ Syst 2001;23(7):565-75.

[29] Soke A, Bingul Z. Hybrid genetic algorithm and simulated annealing for two-dimensional non-guillotine rectangular packing problems. Eng Appl Artif Intel 2006;19(5):557-67.

[30] Wu TH, Chung SH, Chang CC. Hybrid simulated annealing algorithm with mutation operator to the cell formation problem with alternative process routings. Expert Syst Appl 2009;36(2):3652-61.

[31] Martí JV. Optimal design bridges boards of prestressed concrete precast beams. Doctoral thesis, Universitat Politècnica de València, Construction Engineering Dept., 2010.

[32] Perea C, Yepes V, Alcala J, Hospitaler A, Gonzalez-Vidosa F. A parametric study of optimum road frame bridges by threshold acceptance. Indian J Eng Mater S 2010;17(6):427-37. 


\section{List of Tables}

Table 1. Main parameters of the analysis.

Table 2. Basic prices of the PC precast road bridge.

Table 3. Cost correction coefficients of steel reinforcement.

Table 4. Costs of beam transport (distance up to $20 \mathrm{~km}$, one way).

Table 5. Beam placing cost.

Table 6. Results of the SAMO algorithm for 16 parameter combinations.

Table 7. SAMO best solutions for 20-25-30-35-40 m spans.

Table 8. SAMO basic measurements for 20-25-30-35-40 $\mathrm{m}$ spans.

Table 9. Reinforcement at support cross-section.

Table 10. SAMO average results for $35 \mathrm{~m}$ span considering different economic scenarios for steel prices $(\mathrm{S})$ and concrete prices $(\mathrm{C})$.

\section{List of Figures}

Fig. 1. PC precast road bridge cross-section.

Fig. 2. Geometrical variables, active and passive reinforcement variables, and parameters.

Fig. 3. Main beam-slab geometric parameters.

Fig. 4. Structural model detail for deck analysis.

Fig. 5. Flowchart of the hybrid simulated annealing process.

Fig. 6. Typical cost variation and temperature reduction with computing time for SAMO algorithm.

Fig. 7. Mean cost for different span lengths.

Fig. 8. Mean depth of the beam for different span lengths.

Fig. 9. Mean thickness of the slab for different span lengths.

Fig. 10. Average number of strands in relation to the span length.

Fig. 11. Mean characteristic compressive strength of concrete for different span lengths.

Fig. 12. Variation in the mean width of the soffit of the beam with the span.

Fig. 13. Variation in the mean thickness of the bottom flange with the span.

Fig. 14. Variation in the ratio of the volume of concrete in relation to the surface of the slab with the span.

Fig. 15. Variation in the ratio of the passive reinforcement in relation to the surface of the slab with the span.

Fig. 16. Variation in the cost for a PC precast bridge (35 $\mathrm{m}$ span) for increases in steel and concrete prices.

Fig. 17. Variation in the steel reinforcement in relation to the surface of the slab for a PC bridge ( $35 \mathrm{~m} \mathrm{span})$ for increases in steel and concrete prices.

Fig. 18. Variation in the volume of concrete in relation to the surface of the slab for a PC bridge (35 $\mathrm{m}$ span) for increases in steel and concrete prices. 


\section{Table 1}

Main parameters of the analysis.

\section{Geometric parameters}

PC precast bridge width

$$
\begin{aligned}
& W=12.00 \mathrm{~m} \\
& L=35.00 \mathrm{~m} \\
& n_{s 3}=3 \\
& s_{3}=3 \\
& n_{i 3}=3 \\
& i_{4}=4 \\
& 80^{\circ} \\
& L / 18 \\
& s_{v}=6.00 \mathrm{~m} \\
& 0.47 \mathrm{~m}
\end{aligned}
$$

Span length

Inclination, top flange tablet

Top flange division

Inclination, bottom flange tablet

Bottom flange division

Web inclination

Minimum beam slenderness

Spacing between beams

Bearing center to beam face distance

\section{Loading related parameters}

Concrete bridge barrier width

$2 \times 0.50 \mathrm{~m}$

Thickness of wearing surface

$t_{w s}=0.09 \mathrm{~m}$

Concrete bridge barrier loads

$2 \times 5.0 \mathrm{kN} / \mathrm{m}^{2}$

\section{Cost parameters}

Transport distance (one way)

$T_{d}=20 \mathrm{~km}$

Active prestressing steel crops

$25 \%$

\section{Reinforcement parameters}

Passive reinforcing steel (B-500-S)

$f_{y k}=500 \mathrm{~N} / \mathrm{mm}^{2}$

Active prestressing steel (Y1860-S7)

$f_{p k}=1700 \mathrm{~N} / \mathrm{mm}^{2}$

Strand diameter

$\Phi_{s}=0.6 "$

Beam surface reinforcement

$\Phi_{r}=8 \mathrm{~mm}$

Strand sheaths

Levels 2 and 3

Stirrups, vertical slenderness

200 (length/diameter)

\section{Legislative related parameters}

Code regulation

EHE/IAP-98

\section{Exposure related parameters}

External ambient conditions

IIb (EHE) 


\section{Table 2}

Basic prices of the PC precast road bridge.

\begin{tabular}{lr}
\hline Unit & Cost $(€)$ \\
\hline Kg of beam steel (B-500-S) & 2.63 \\
Kg of slab steel (B-500-S) & 1.40 \\
Kg of active steel (Y1860-S7) & 3.38 \\
$\mathrm{~m}$ of beam formwork & 75.11 \\
$\mathrm{~m}^{2}$ of slab formwork & 30.00 \\
$\mathrm{~m}^{3}$ of slab concrete HA-25 & 64.99 \\
$\mathrm{~m}^{3}$ of slab concrete HA-30 & 69.95 \\
$\mathrm{~m}^{3}$ of slab concrete HA-35 & 74.03 \\
$\mathrm{~m}^{3}$ of slab concrete HA-40 & 79.12 \\
$\mathrm{~m}^{3}$ of beam concrete HP-35 & 122.25 \\
$\mathrm{~m}^{3}$ of beam concrete HP-40 & 133.40 \\
$\mathrm{~m}^{3}$ of beam concrete HP-45 & 142.15 \\
$\mathrm{~m}^{3}$ of beam concrete HP-50 & 152.89 \\
\hline
\end{tabular}


Table 3

Cost correction coefficients of steel reinforcement.

\begin{tabular}{lcccc}
\hline $\begin{array}{l}\text { Diameter } \\
(\mathrm{mm})\end{array}$ & \multicolumn{2}{c}{ Beam correction } & \multicolumn{2}{c}{ Slab correction } \\
\cline { 2 - 5 } & Material & Labor & Material & Labor \\
\hline D6 & 1.250 & 1.400 & 1.250 & 1.400 \\
D8 & 1.170 & 1.250 & 1.170 & 1.250 \\
D10 & 1.075 & 1.100 & 1.075 & 1.100 \\
D12 & 1.000 & 1.000 & 1.000 & 1.000 \\
D16 & 0.980 & 0.900 & 0.980 & 0.900 \\
D20 & 0.980 & 0.900 & 0.980 & 0.900 \\
D25 & - & - & 1.000 & 0.800 \\
D32 & - & - & 1.000 & 0.800 \\
\hline
\end{tabular}


Table 4

Table 4

Costs of beam transport (distance up to $20 \mathrm{~km}$, one way).

\begin{tabular}{cc}
\hline $\begin{array}{c}\text { Maximum beam } \\
\text { weigh }(\mathrm{kN})\end{array}$ & $\begin{array}{c}\text { Transport } \\
\text { cost }(€)\end{array}$ \\
\hline 550 & 975 \\
660 & 1275 \\
800 & 1650 \\
1000 & 1825 \\
2000 & 2825 \\
4000 & 3825 \\
\hline
\end{tabular}


Table 5

Table 5

Beam placing cost.

\begin{tabular}{cc}
\hline $\begin{array}{c}\text { Maximum beam } \\
\text { length }(\mathrm{m})\end{array}$ & $\begin{array}{c}\text { Placing } \\
\text { cost }(€)\end{array}$ \\
\hline 20 & 2900 \\
25 & 3000 \\
30 & 5100 \\
35 & 5200 \\
40 & 6200 \\
\hline
\end{tabular}




\section{Table 6}

Results of the SAMO algorithm for 16 parameter combinations.

\begin{tabular}{crrrrrc}
\hline $\begin{array}{c}\text { Heuristic } \\
\text { number }\end{array}$ & $r$ & $L_{M}$ & $\begin{array}{c}\text { Average cost } \\
\text { (euros) }\end{array}$ & $\begin{array}{r}\text { Average } \\
\text { time (s) }\end{array}$ & $\begin{array}{c}\text { Minimum cost } \\
\text { (euros) }\end{array}$ & $\begin{array}{c}\text { Deviation } \\
\text { (\%) }\end{array}$ \\
S1 & 0.95 & 500 & 116,066 & 3,224 & 113,284 & 2.46 \\
S2 & 0.95 & 1,000 & 112,064 & 7,442 & 110,049 & 1.83 \\
S3 & 0.95 & 2,500 & 110,477 & 18,322 & 109,004 & 1.35 \\
S4 & 0.95 & 5,000 & 110,919 & 36,163 & 109,117 & 1.65 \\
S5 & 0.90 & 500 & 121,909 & 1,675 & 114,905 & 6.10 \\
S6 & 0.90 & 1,000 & 114,839 & 3,720 & 111,651 & 2.86 \\
S7 & 0.90 & 2,500 & 111,743 & 9,147 & 109,119 & 2.41 \\
S8 & 0.90 & 5,000 & 110,759 & 18,875 & 109,810 & 0.86 \\
S9 & 0.85 & 500 & 123,223 & 1,184 & 117,632 & 4.75 \\
S10 & 0.85 & 1,000 & 119,268 & 2,940 & 111,143 & 7.31 \\
S11 & 0.85 & 2,500 & 114,308 & 6,574 & 109,875 & 4.04 \\
S12 & 0.85 & 5,000 & 111,903 & 12,986 & 108,008 & 3.61 \\
S13 & 0.80 & 500 & 125,160 & 946 & 114,626 & 9.19 \\
S14 & 0.80 & 1,000 & 121,381 & 2,366 & 109,938 & 10.41 \\
S15 & 0.80 & 2,500 & 115,130 & 4,967 & 111,197 & 3.54 \\
S16 & 0.80 & 5,000 & 112,194 & 10,743 & 109,134 & 2.80 \\
\hline
\end{tabular}




\section{Table 7}

SAMO best solutions for 20-25-30-35-40 m spans.

\begin{tabular}{ccccccccccccccc}
\hline $\begin{array}{c}\text { Span } \\
(\mathrm{m})\end{array}$ & $\begin{array}{c}\text { Cost } \\
(\mathrm{euros})\end{array}$ & $\begin{array}{c}h_{1} \\
(\mathrm{~m})\end{array}$ & $\begin{array}{c}e_{4} \\
(\mathrm{~m})\end{array}$ & $\begin{array}{c}b_{1} \\
(\mathrm{~m})\end{array}$ & $\begin{array}{c}b_{3} \\
(\mathrm{~m})\end{array}$ & $\begin{array}{c}e_{1} \\
(\mathrm{~m})\end{array}$ & $\begin{array}{c}e_{2} \\
(\mathrm{~m})\end{array}$ & $\begin{array}{c}e_{3} \\
(\mathrm{~m})\end{array}$ & $\begin{array}{c}f_{\mathrm{c}, \text { beam }} \\
(\mathrm{MPa})\end{array}$ & $\begin{array}{c}f_{\mathrm{c}, \mathrm{slab}} \\
(\mathrm{MPa})\end{array}$ & $\begin{array}{c}p_{1} \\
(\mathrm{n})\end{array}$ & $\begin{array}{c}p_{2} \\
(\mathrm{n})\end{array}$ & $\begin{array}{c}p_{3} \\
(\mathrm{n})\end{array}$ & $\begin{array}{c}p_{4} \\
(\mathrm{n})\end{array}$ \\
\hline 20 & 61,677 & 1.09 & 0.21 & 1.99 & 0.26 & 0.15 & 0.10 & 0.19 & 50 & 40 & 35 & 0 & 0 & 2 \\
25 & 74,394 & 1.38 & 0.21 & 2.00 & 0.25 & 0.15 & 0.10 & 0.18 & 45 & 35 & 37 & 4 & 0 & 4 \\
30 & 91,413 & 1.64 & 0.22 & 2.00 & 0.32 & 0.17 & 0.10 & 0.26 & 45 & 40 & 37 & 13 & 0 & 2 \\
35 & 109,004 & 1.94 & 0.19 & 1.99 & 0.29 & 0.18 & 0.10 & 0.23 & 40 & 40 & 36 & 20 & 0 & 2 \\
40 & 126,036 & 2.22 & 0.19 & 1.99 & 0.28 & 0.21 & 0.10 & 0.22 & 40 & 40 & 36 & 28 & 0 & 2 \\
\hline
\end{tabular}




\section{Table 8}

SAMO basic measurements for 20-25-30-35-40 m spans.

\begin{tabular}{cccccc}
\hline $\begin{array}{c}\text { Span } \\
(\mathrm{m})\end{array}$ & $\begin{array}{c}\text { Beam } \\
\text { reinforcement }(\mathrm{kg})\end{array}$ & $\begin{array}{c}\text { Slab reinforcement } \\
(\mathrm{kg})\end{array}$ & $\begin{array}{c}\text { Total reinforcement } \\
\left(\mathrm{kg} / \mathrm{m}^{2}\right)\end{array}$ & $\begin{array}{c}\text { Beam concrete } \\
\left(\mathrm{m}^{3} / \mathrm{m}^{2}\right)\end{array}$ & $\begin{array}{c}\text { Slab concrete } \\
\left(\mathrm{m}^{3} / \mathrm{m}^{2}\right)\end{array}$ \\
\hline 20 & 2,454 & 12,756 & 60.36 & 0.097 & 0.21 \\
25 & 3,237 & 14,949 & 58.29 & 0.106 & 0.21 \\
30 & 4,230 & 15,286 & 52.47 & 0.132 & 0.22 \\
35 & 6,164 & 19,668 & 59.80 & 0.140 & 0.19 \\
40 & 7,303 & 21,679 & 58.91 & 0.157 & 0.19 \\
\hline
\end{tabular}




\section{Table 9}

Reinforcement at support cross-section.

\begin{tabular}{cccccccc}
\hline Span $(\mathrm{m})$ & As6 & As7 & $t_{1}(\mathrm{~m})$ & $t_{2}$ & $t_{3}$ & $t_{4}$ & $t_{5}$ \\
\hline 20 & $73 \varnothing 25$ & $49 \varnothing 6$ & $2 \varnothing 8 / 200 \mathrm{~mm}$ & $2 \varnothing 10 / 200 \mathrm{~mm}$ & $\varnothing 8 / 200 \mathrm{~mm}$ & $\varnothing 25 / 300 \mathrm{~mm}$ & $\varnothing 25 / 300 \mathrm{~mm}$ \\
25 & $61 \varnothing 25$ & $49 \varnothing 6$ & $\varnothing 12 / 200 \mathrm{~mm}$ & $\varnothing 12 / 200 \mathrm{~mm}$ & $\varnothing 8 / 200 \mathrm{~mm}$ & $\varnothing 25 / 250 \mathrm{~mm}$ & $\varnothing 25 / 250 \mathrm{~mm}$ \\
30 & $85 \varnothing 20$ & $49 \varnothing 6$ & $\varnothing 12 / 200 \mathrm{~mm}$ & $\varnothing 12 / 200 \mathrm{~mm}$ & $\varnothing 6 / 200 \mathrm{~mm}$ & $\varnothing 16 / 150 \mathrm{~mm}$ & $2 \varnothing 16 / 250 \mathrm{~mm}$ \\
35 & $85 \varnothing 20$ & $49 \varnothing 6$ & $\varnothing 16 / 200 \mathrm{~mm}$ & $\varnothing 12 / 200 \mathrm{~mm}$ & $\varnothing 6 / 200 \mathrm{~mm}$ & $\varnothing 25 / 300 \mathrm{~mm}$ & $\varnothing 25 / 300 \mathrm{~mm}$ \\
40 & $49 \varnothing 25$ & $49 \varnothing 6$ & $\varnothing 12 / 200 \mathrm{~mm}$ & $\varnothing 12 / 200 \mathrm{~mm}$ & $\varnothing 6 / 200 \mathrm{~mm}$ & $\varnothing 25 / 300 \mathrm{~mm}$ & $\varnothing 25 / 300 \mathrm{~mm}$ \\
\hline
\end{tabular}




\section{Table 10}

SAMO average results for $35 \mathrm{~m}$ span considering different economic scenarios for steel prices (S) and concrete prices $(\mathrm{C})$.

\begin{tabular}{ccccccccccccccc}
\hline Scenario & $\begin{array}{c}\text { Cost } \\
(\mathrm{euros})\end{array}$ & $\begin{array}{c}h_{1} \\
(\mathrm{~m})\end{array}$ & $\begin{array}{c}e_{4} \\
(\mathrm{~m})\end{array}$ & $\begin{array}{c}b_{1} \\
(\mathrm{~m})\end{array}$ & $\begin{array}{c}b_{3} \\
(\mathrm{~m})\end{array}$ & $\begin{array}{c}e_{1} \\
(\mathrm{~m})\end{array}$ & $\begin{array}{c}e_{2} \\
(\mathrm{~m})\end{array}$ & $\begin{array}{c}e_{3} \\
(\mathrm{~m})\end{array}$ & $\begin{array}{c}f_{\text {c,beam }} \\
(\mathrm{MPa})\end{array}$ & $\begin{array}{c}f_{\mathrm{c}, \mathrm{slab}} \\
(\mathrm{MPa})\end{array}$ & $\begin{array}{c}p_{1} \\
(\mathrm{n})\end{array}$ & $\begin{array}{c}p_{2} \\
(\mathrm{n})\end{array}$ & $\begin{array}{c}p_{3} \\
(\mathrm{n})\end{array}$ & $\begin{array}{c}p_{4} \\
(\mathrm{n})\end{array}$ \\
\hline$\Delta 20 \% \mathrm{~S}$ & 123,537 & 1.89 & 0.23 & 1.94 & 0.28 & 0.19 & 0.10 & 0.21 & 48 & 37 & 35 & 23 & 0 & 2 \\
$\Delta 15 \% \mathrm{~S}$ & 121,232 & 1.91 & 0.23 & 1.95 & 0.27 & 0.19 & 0.10 & 0.20 & 48 & 39 & 35 & 22 & 0 & 2 \\
$\Delta 10 \% \mathrm{~S}$ & 117,746 & 1.90 & 0.22 & 1.95 & 0.28 & 0.19 & 0.10 & 0.21 & 48 & 38 & 36 & 22 & 0 & 2 \\
$\Delta 5 \% \mathrm{~S}$ & 113,918 & 1.91 & 0.22 & 1.97 & 0.28 & 0.19 & 0.10 & 0.21 & 47 & 38 & 36 & 22 & 0 & 2 \\
$0 \%$ & 110,477 & 1.92 & 0.22 & 1.96 & 0.25 & 0.17 & 0.10 & 0.21 & 47 & 37 & 36 & 22 & 0 & 2 \\
$\Delta 5 \% \mathrm{C}$ & 112,222 & 1.92 & 0.22 & 1.95 & 0.26 & 0.20 & 0.10 & 0.19 & 48 & 38 & 35 & 22 & 0 & 2 \\
$\Delta 10 \% \mathrm{C}$ & 112,597 & 1.90 & 0.21 & 1.95 & 0.26 & 0.17 & 0.10 & 0.20 & 48 & 37 & 36 & 21 & 0 & 2 \\
$\Delta 15 \% \mathrm{C}$ & 112,840 & 1.90 & 0.21 & 1.96 & 0.28 & 0.17 & 0.10 & 0.21 & 48 & 38 & 36 & 22 & 0 & 2 \\
$\Delta 20 \% \mathrm{C}$ & 115,116 & 1.91 & 0.22 & 1.97 & 0.25 & 0.19 & 0.10 & 0.18 & 48 & 38 & 36 & 21 & 0 & 2 \\
\hline
\end{tabular}




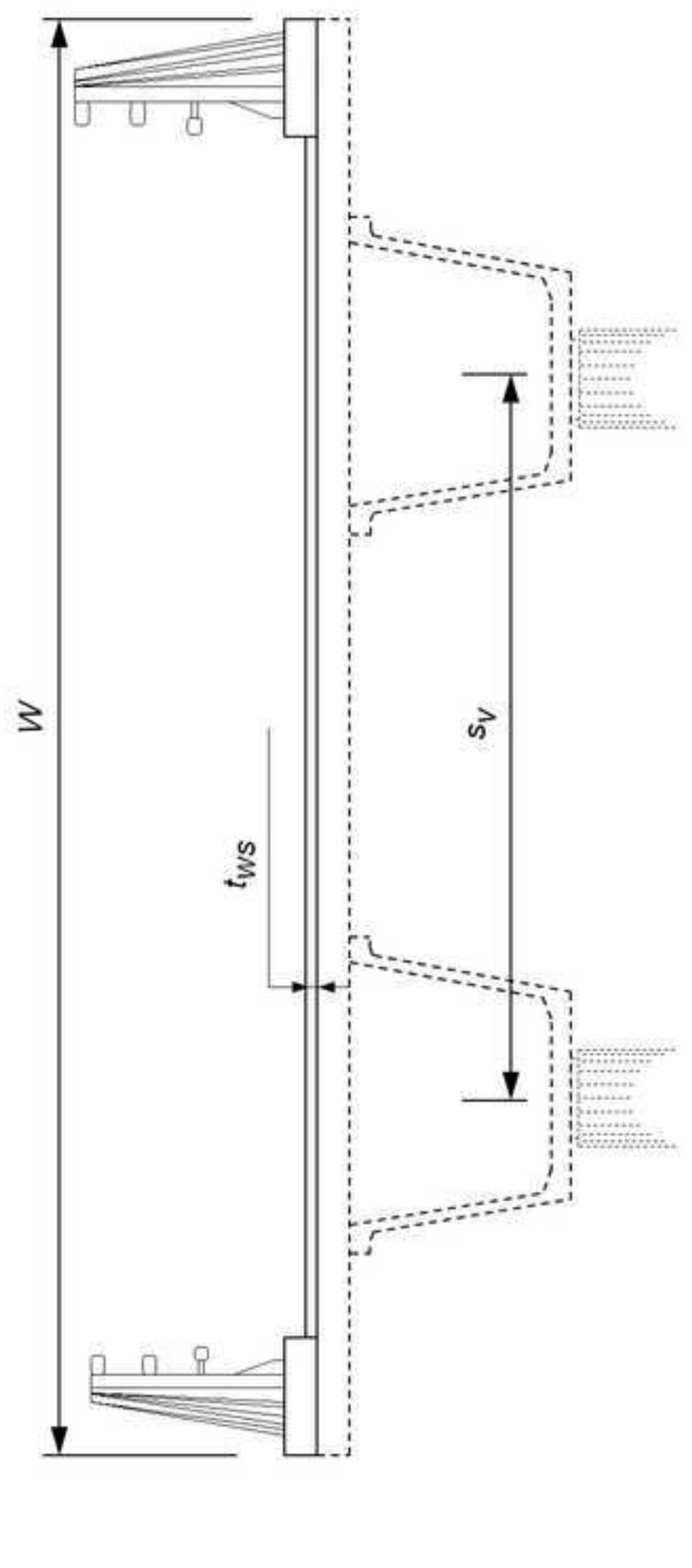




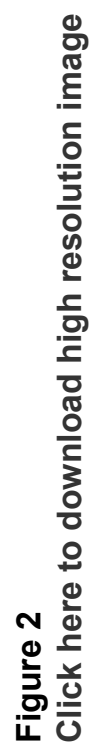

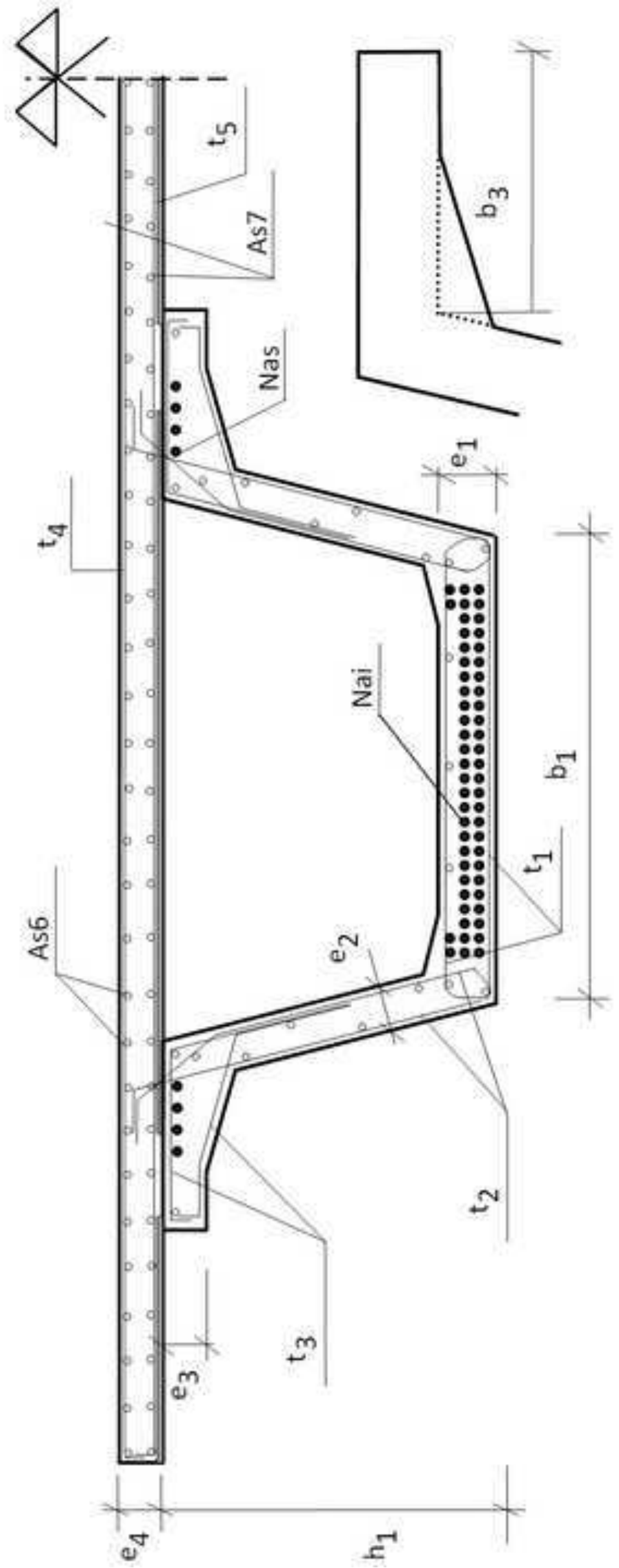




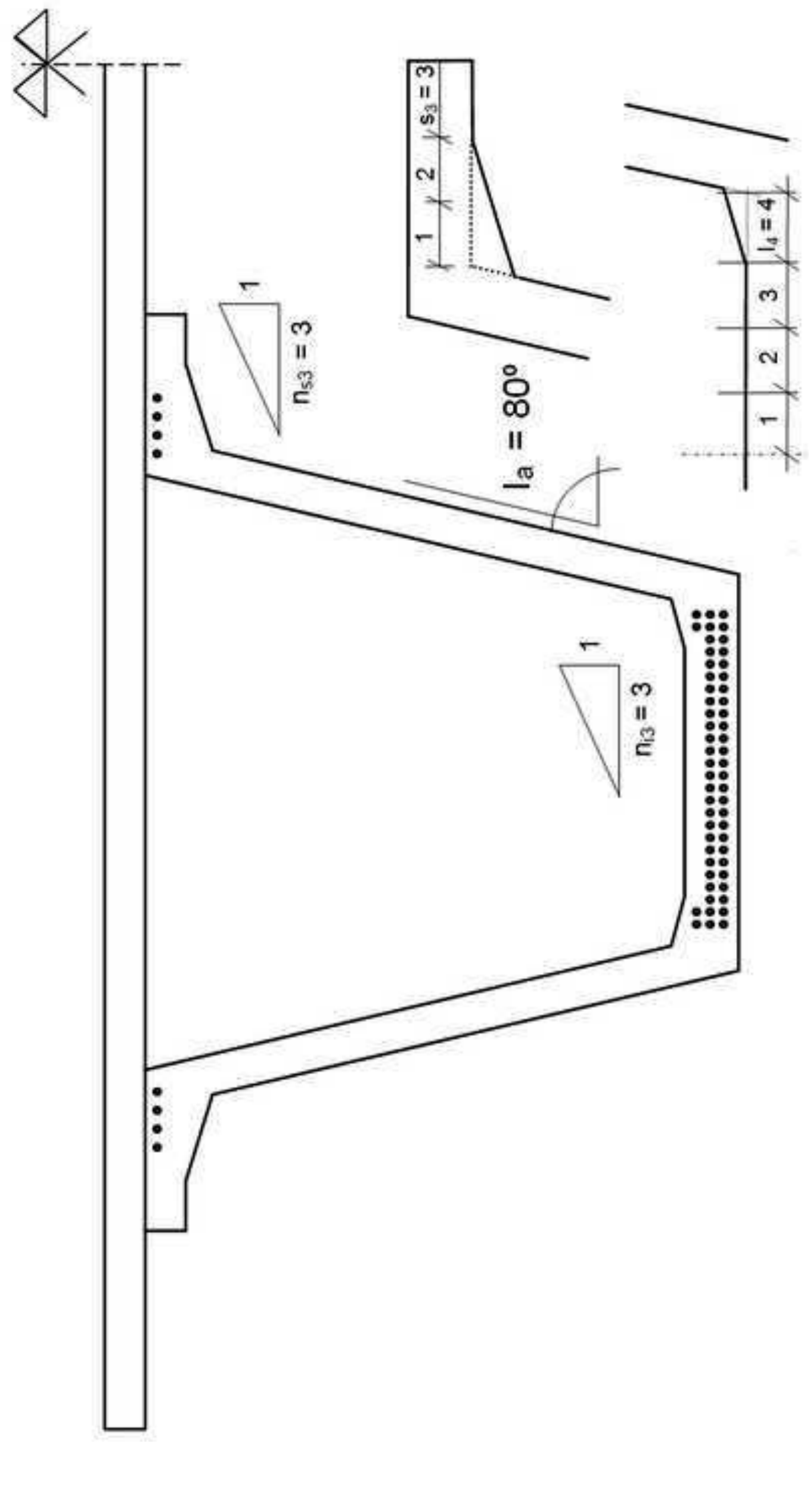




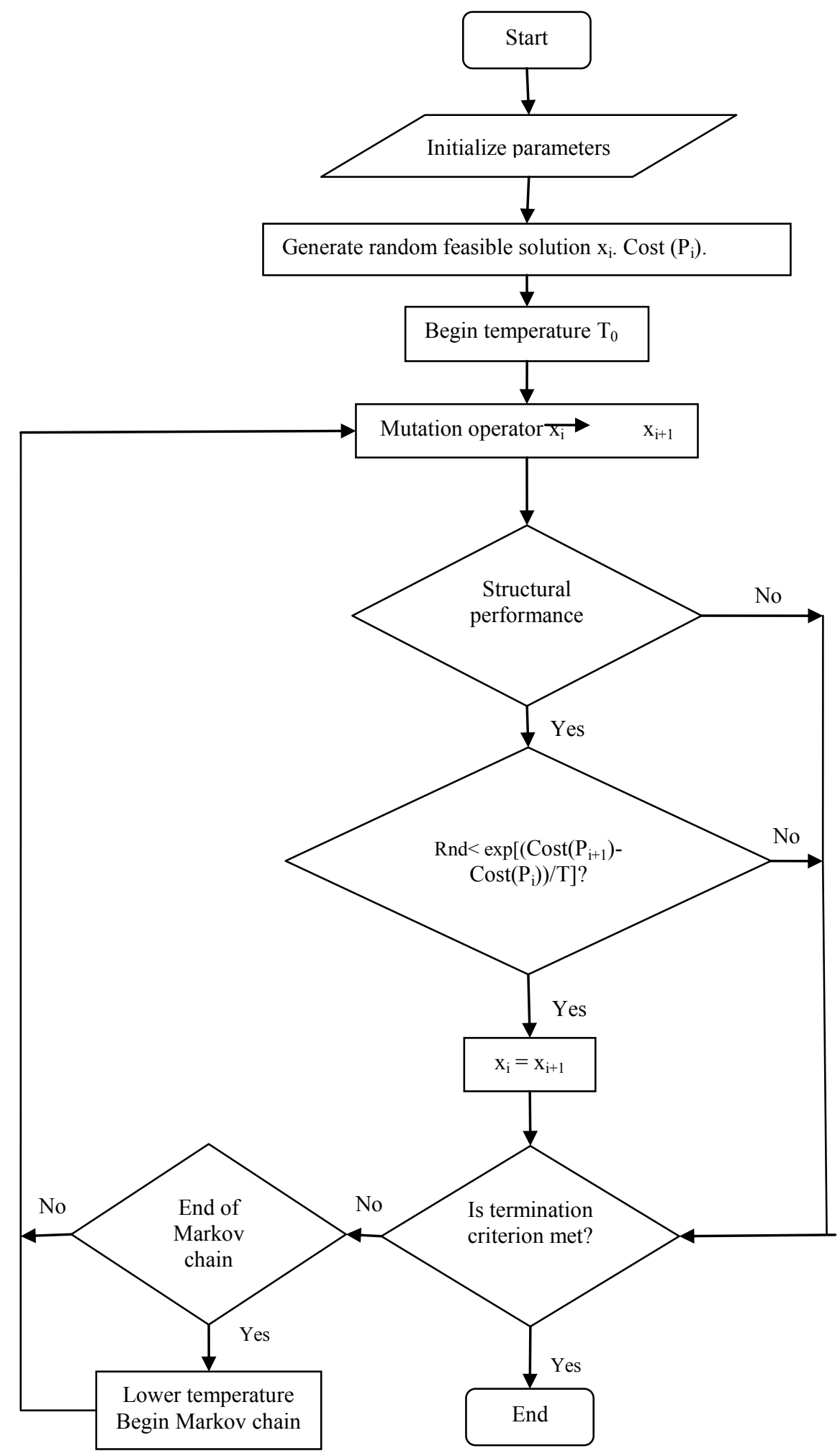

Fig. 5: Flowchart of the hybrid simulated annealing process. 


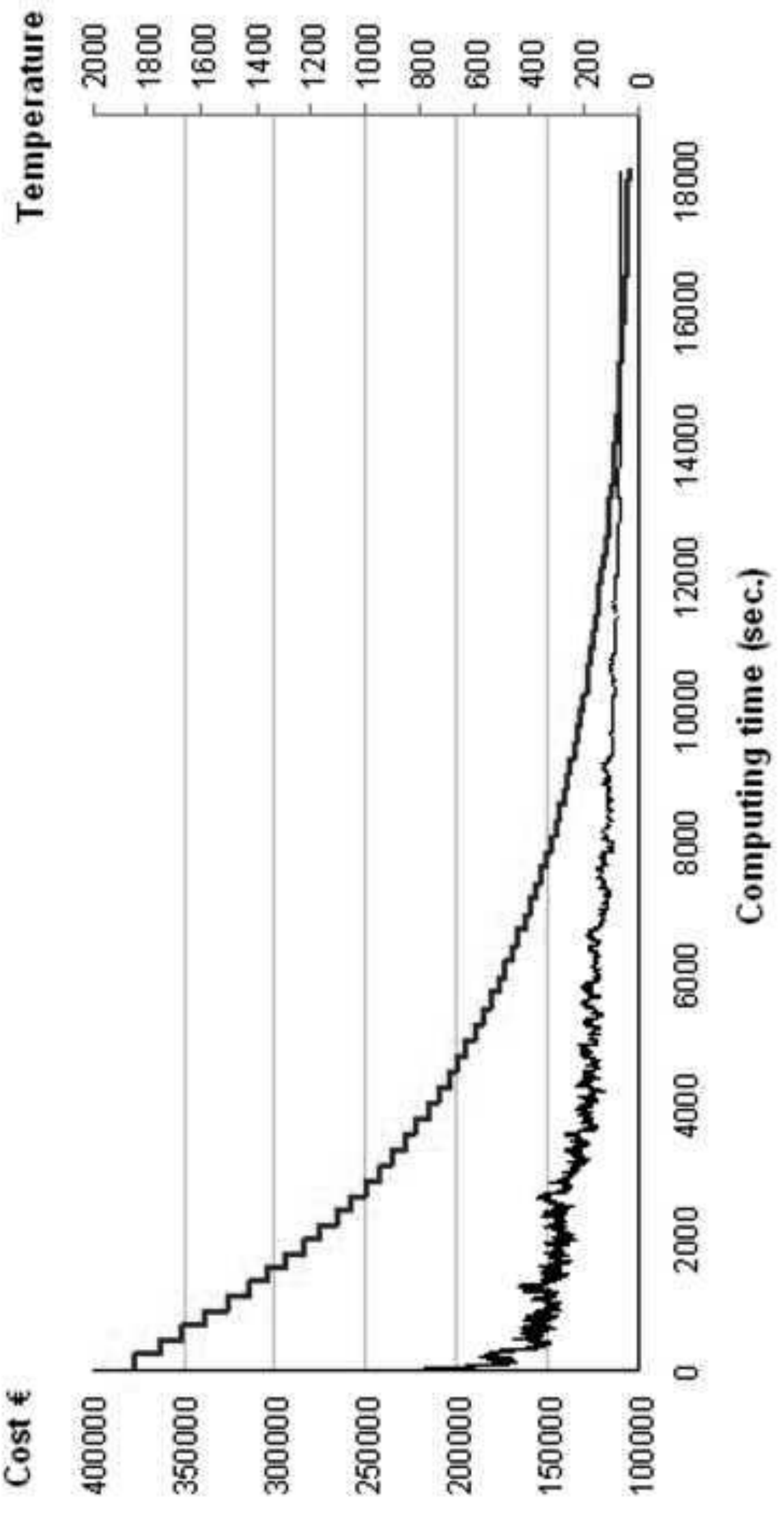

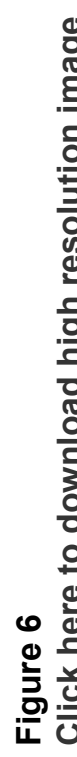




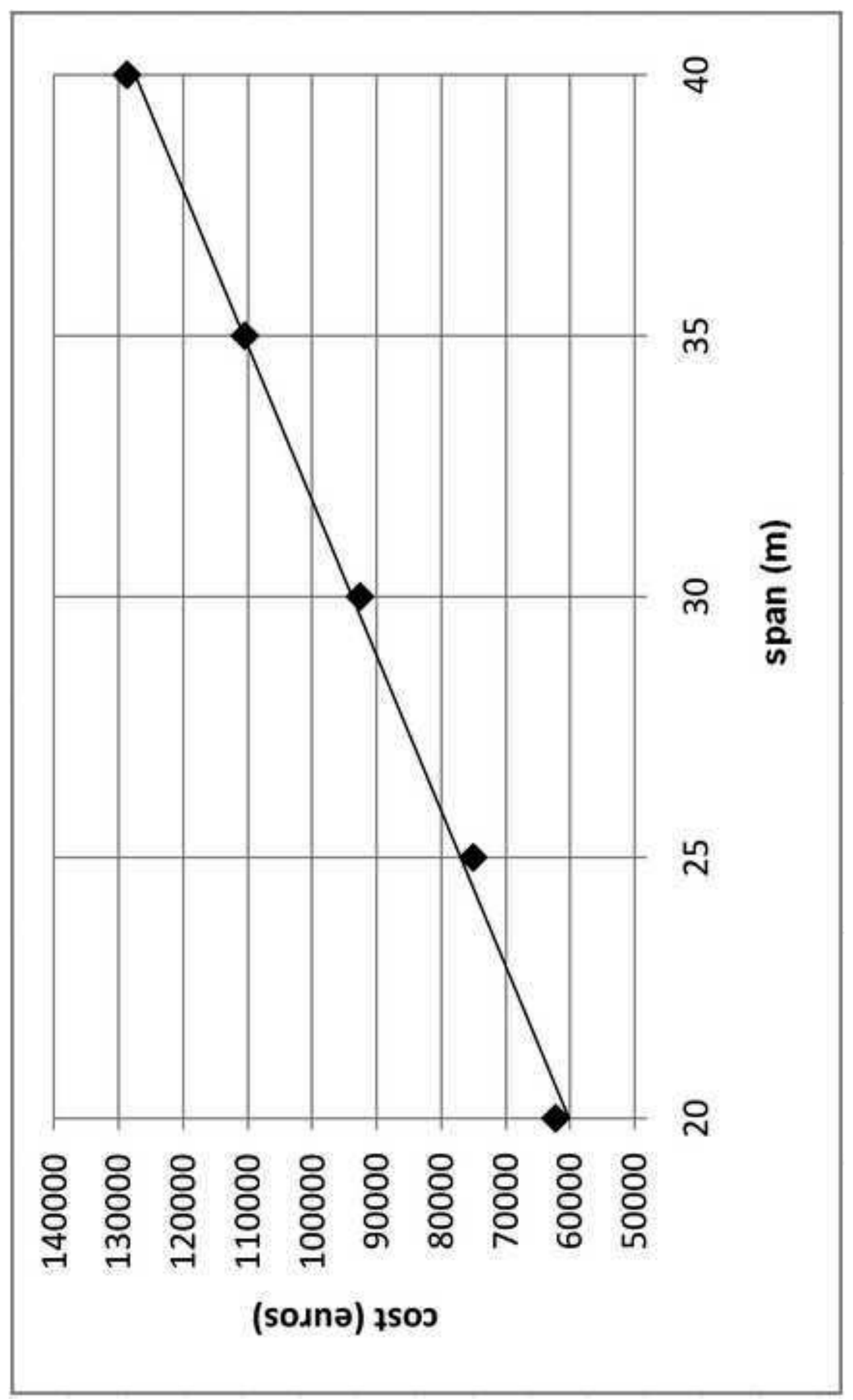

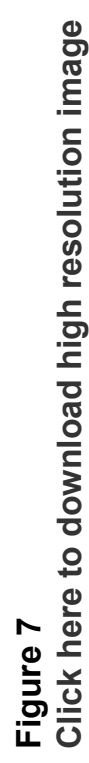




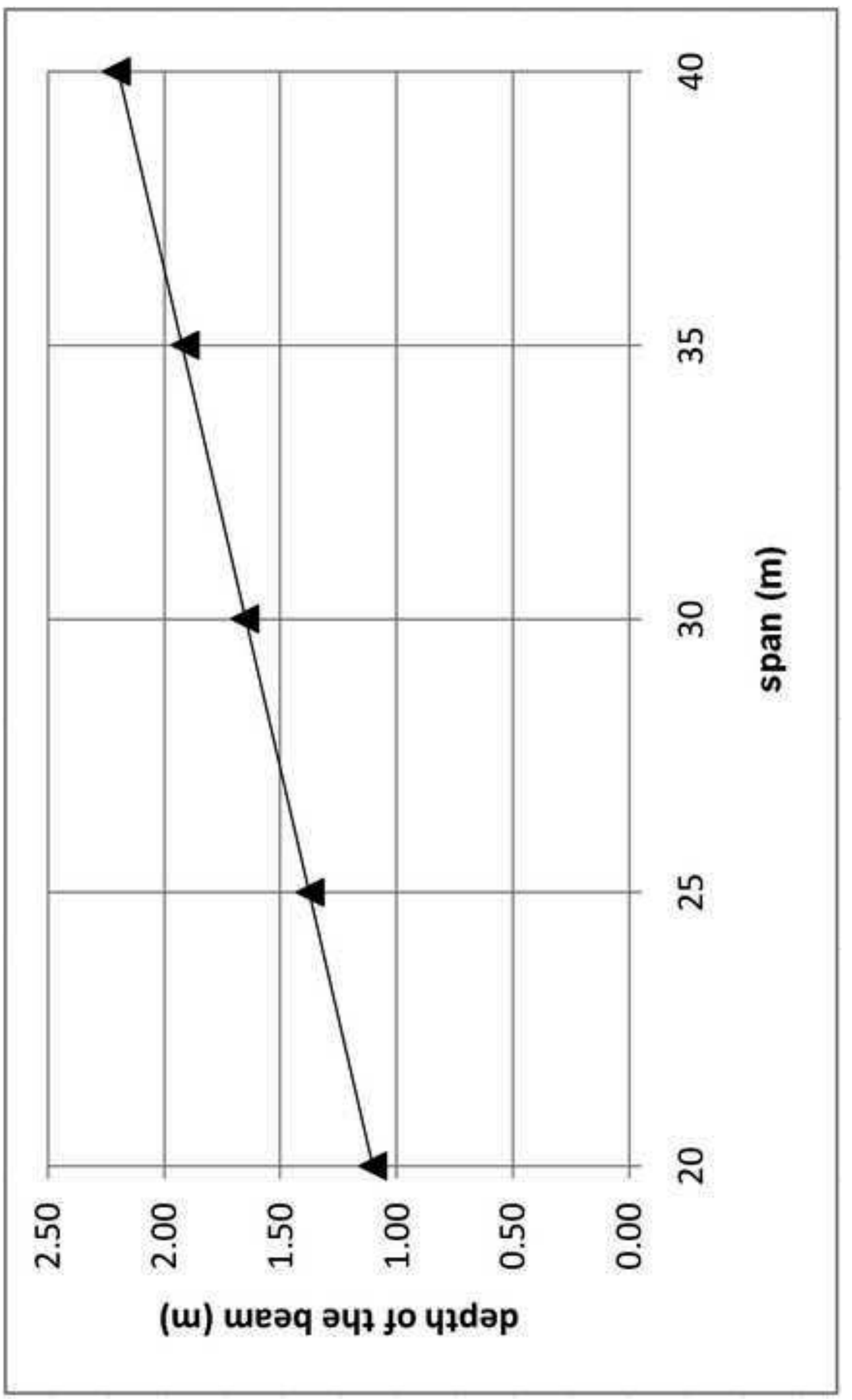

은 


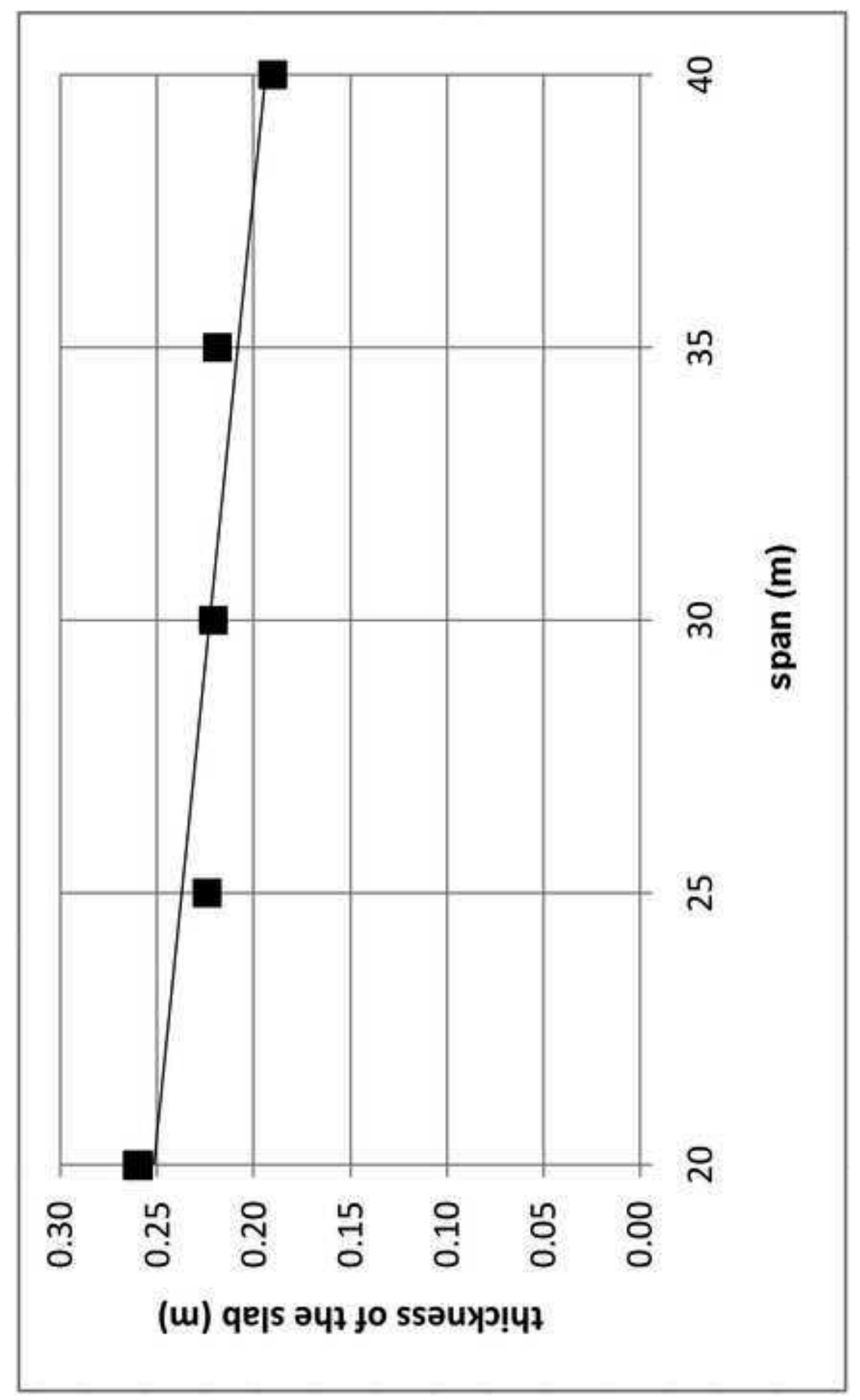
은 

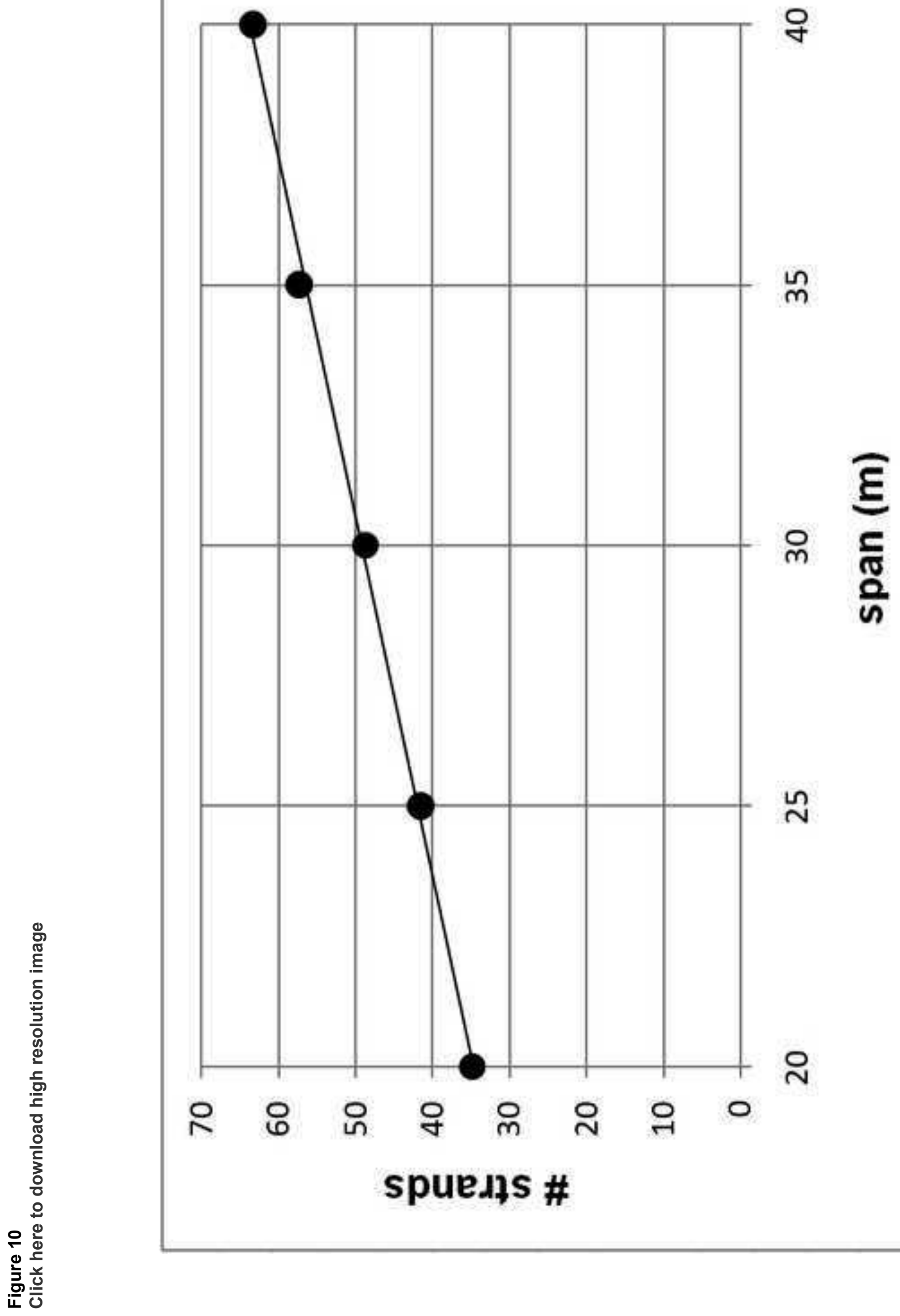

ก

กิ

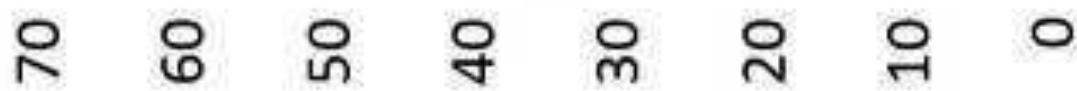

spueds \# 
$\frac{E}{\pi} \frac{1}{0} \frac{\pi}{0}$

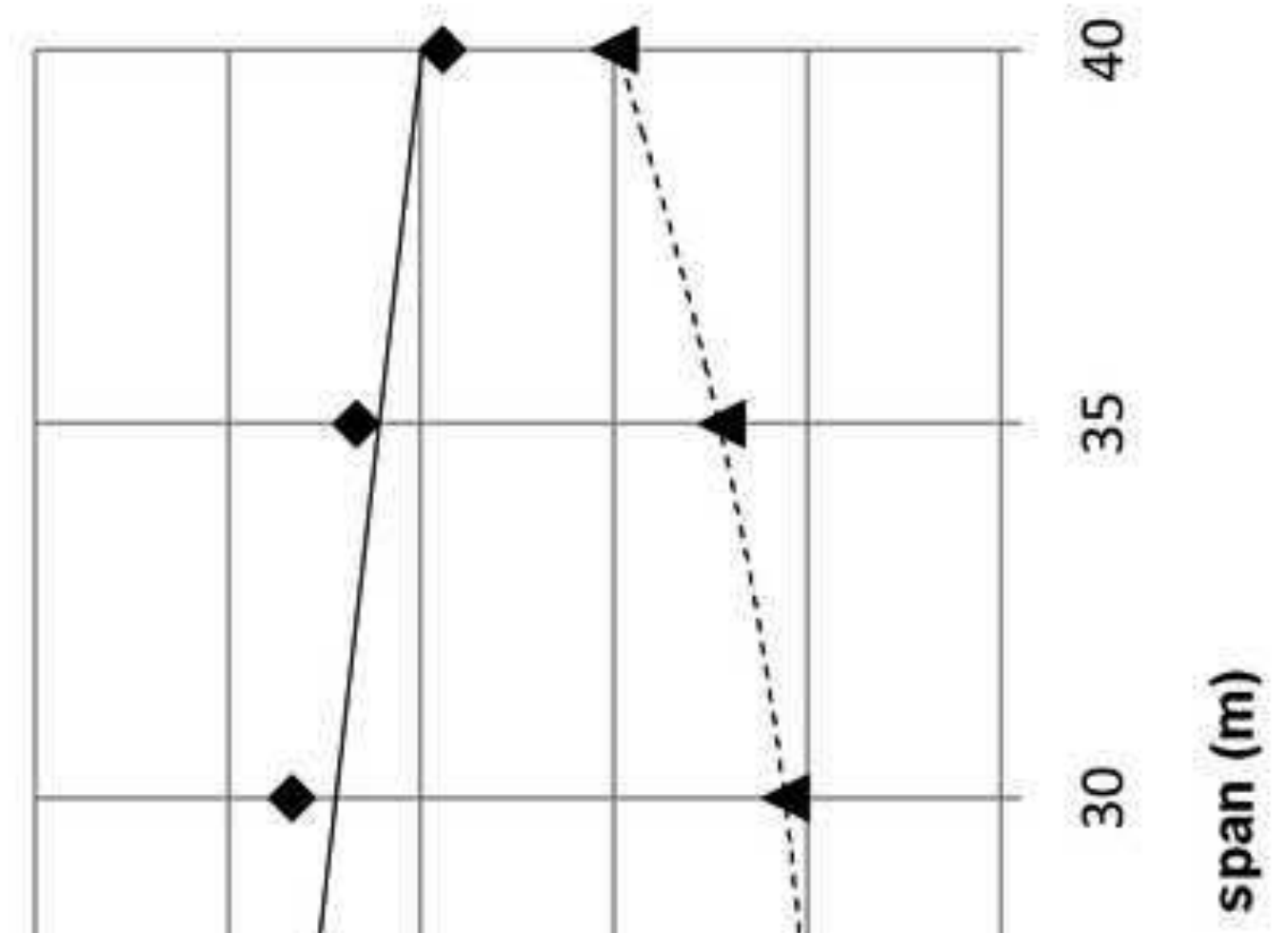

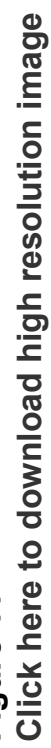




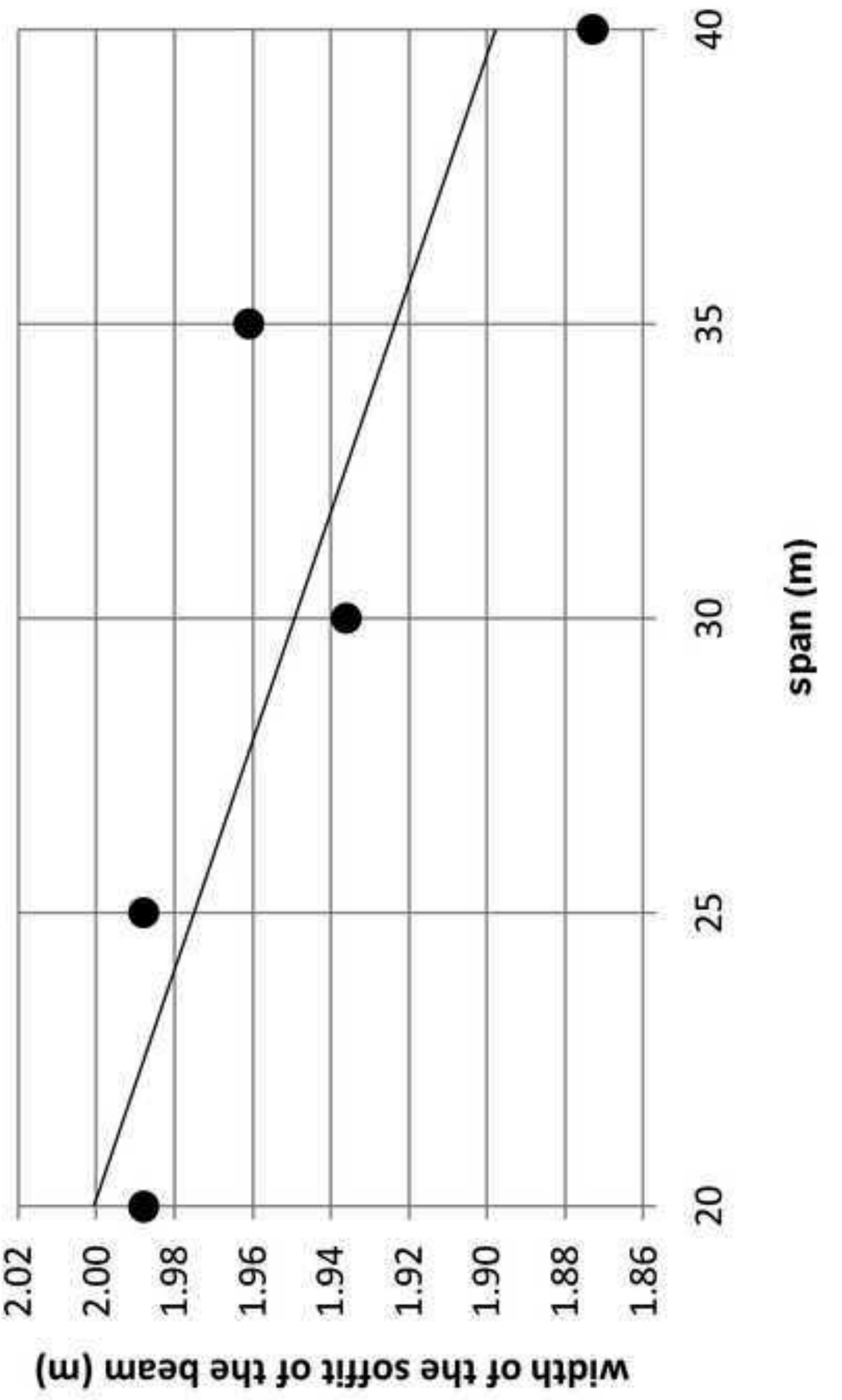




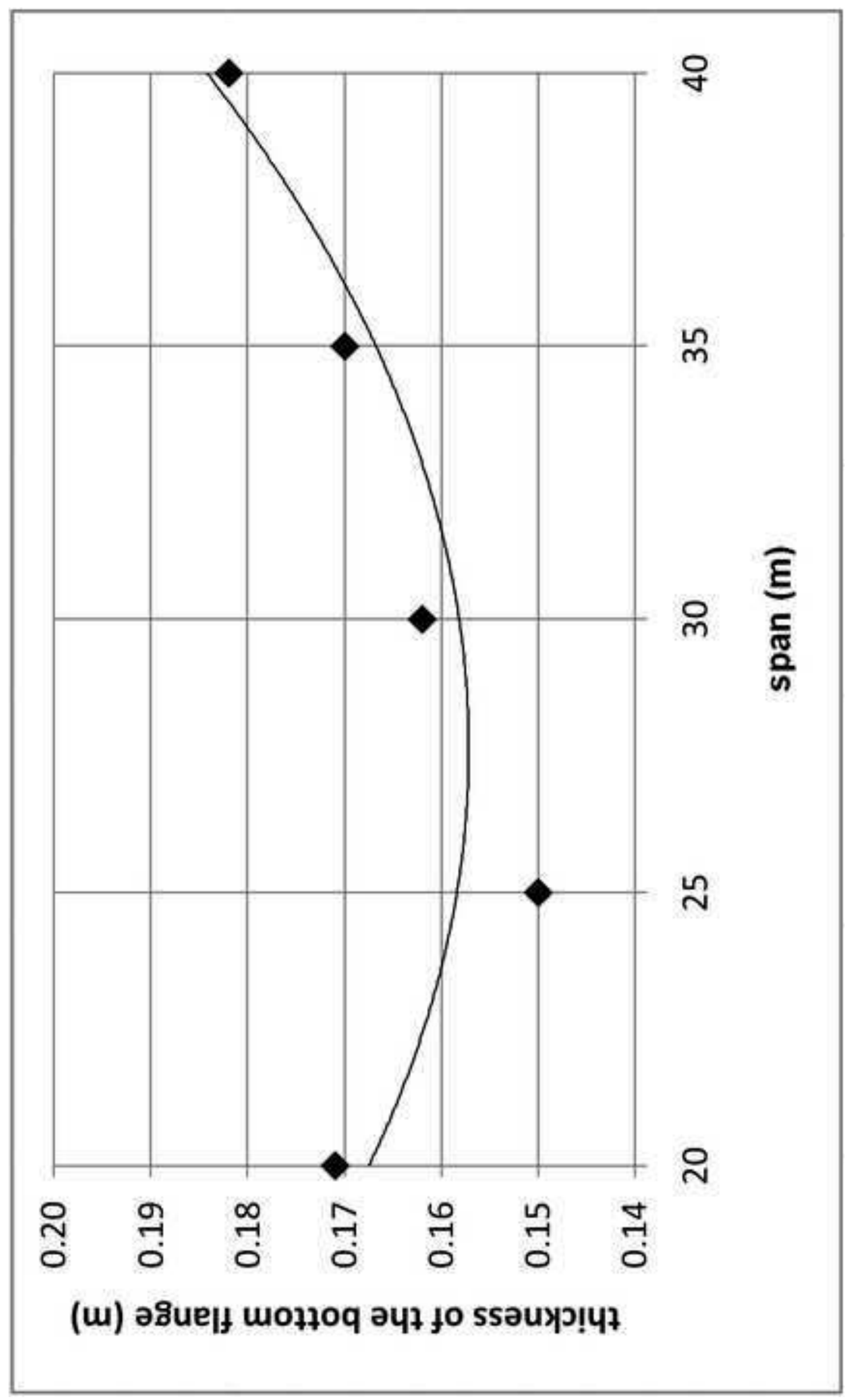

$\stackrel{0}{\circ}$

0

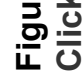




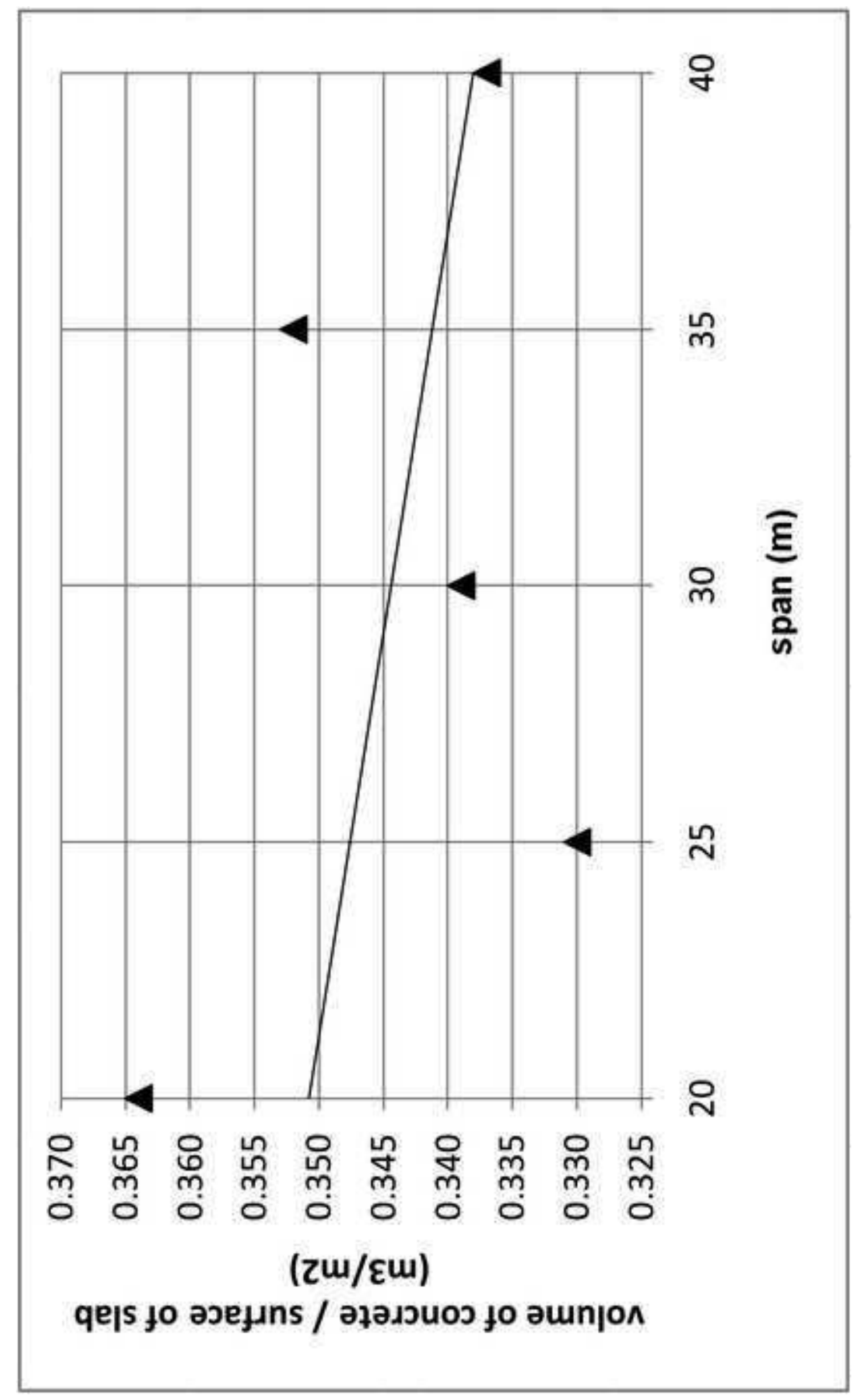




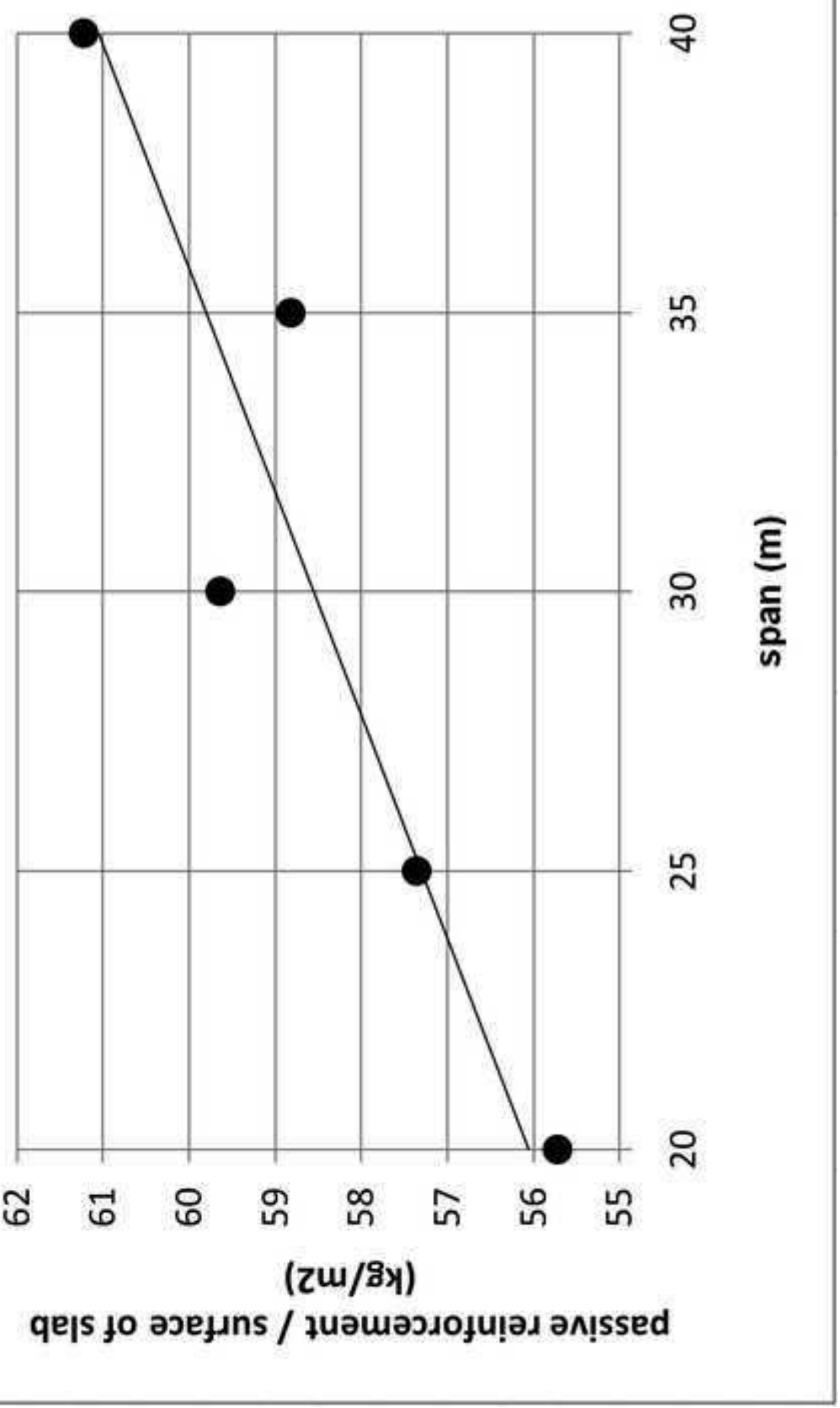

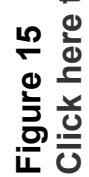




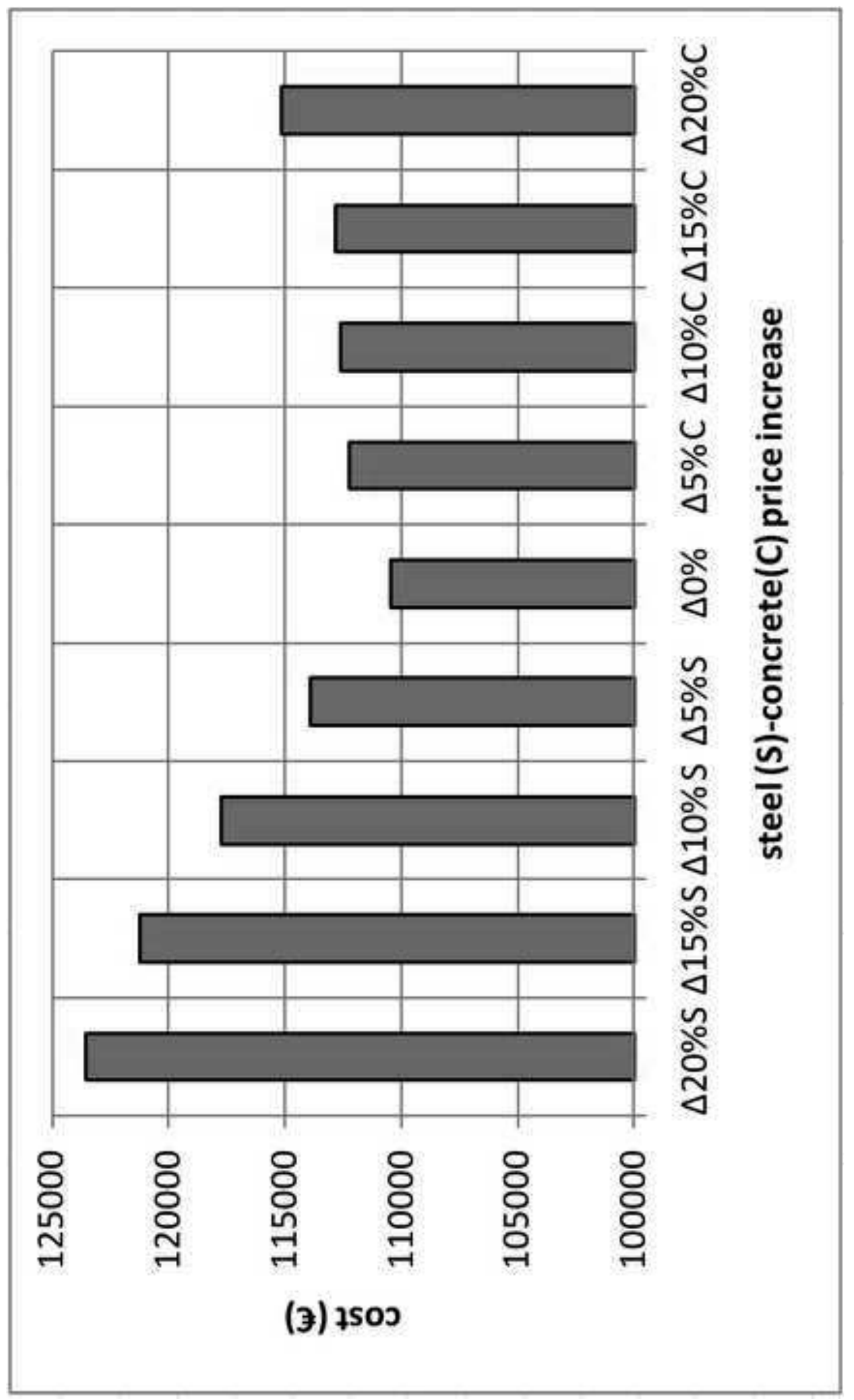

$\stackrel{0}{\circ}$

은

可㒸 


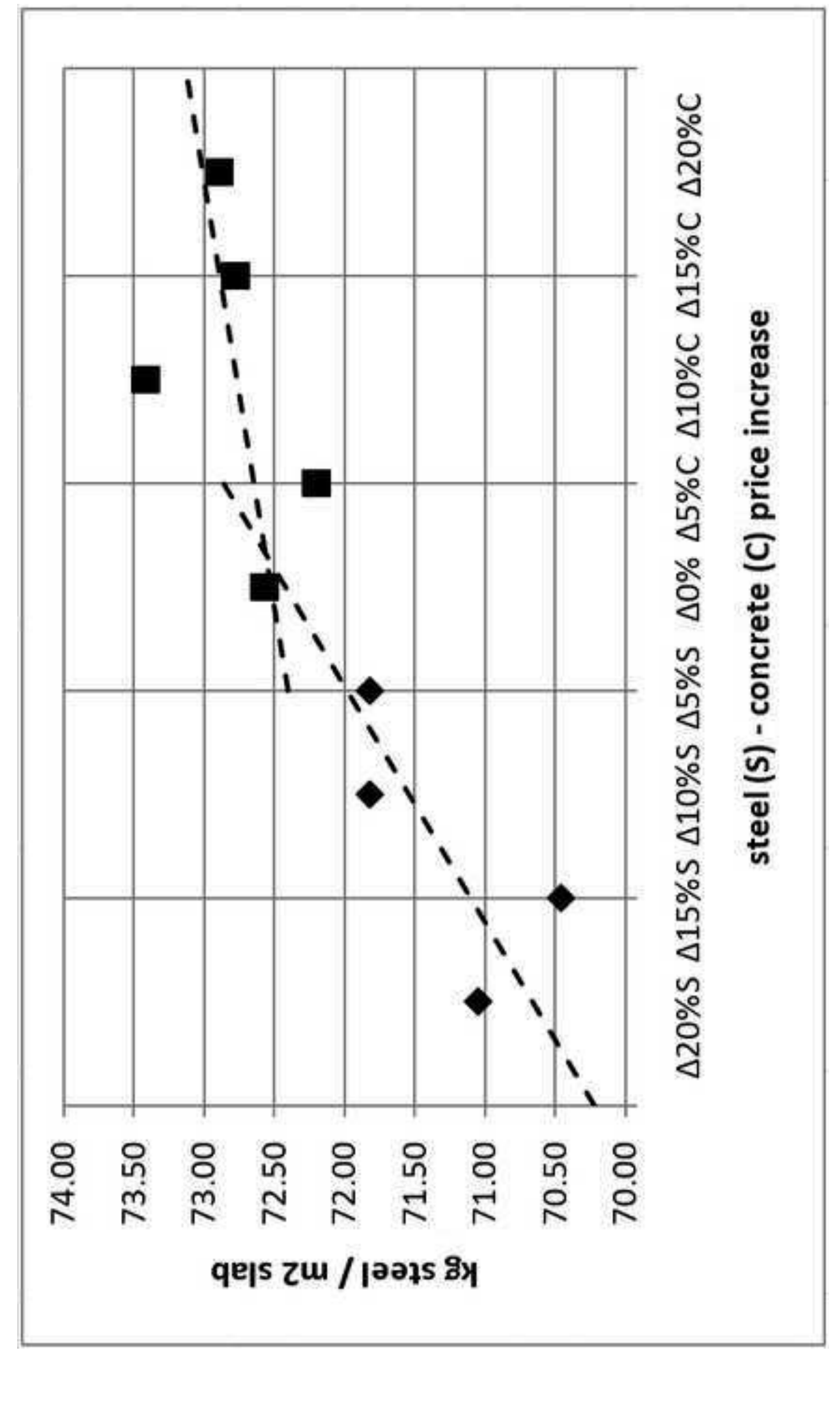




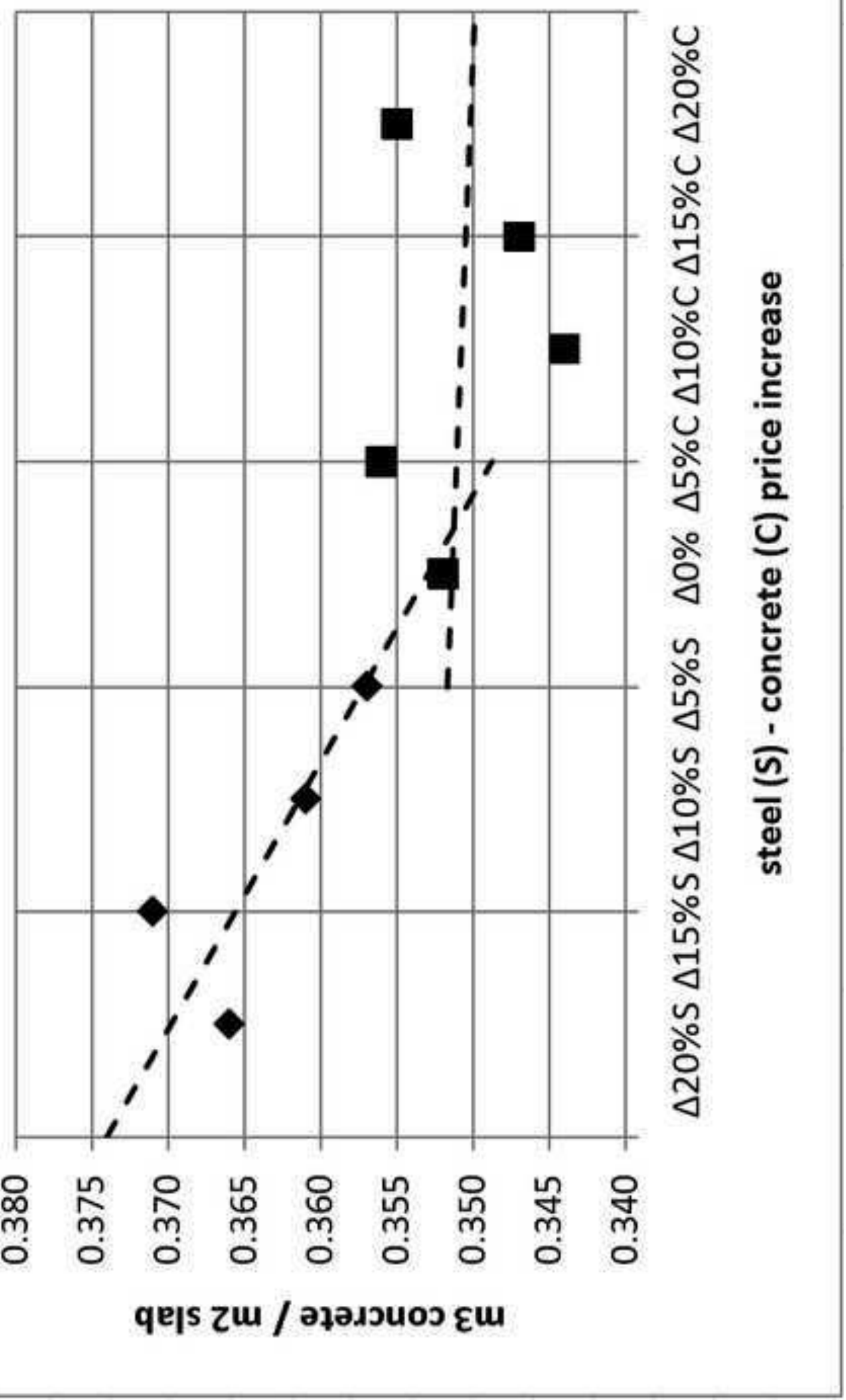

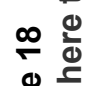

은 은 